GUILHERME SIQUEIRA DE CARVALHO

\title{
O DIREITO DE ACESSO À INFORMAÇÃO E O SIGILO ECONÔMICO NAS EMPRESAS ESTATAIS
}

Dissertação de Mestrado

Orientador: Professor Titular Dr. Fernando Menezes de Almeida

UNIVERSIDADE DE SÃO PAULO

FACULDADE DE DIREITO

São Paulo - SP

2017 

Versão Original

\section{O DIREITO DE ACESSO À INFORMAÇÃO E O SIGILO ECONÔMICO NAS EMPRESAS ESTATAIS}

Dissertação apresentada à Banca Examinadora do Programa de Pós-Graduação em Direito, da Faculdade de Direito da Universidade de São Paulo, como exigência parcial para obtenção do título de Mestre em Direito, na área de concentração Direito do Estado, sob a orientação do Prof. Titular Dr. Fernando Menezes de Almeida. 



\section{AGRADECIMENTOS}

Primeiro fui apresentado ao tema do acesso à informação por meu querido amigo Raphael Soré. Foram nossas longas discussões - primeiro na Corregedoria Geral da Administração e, posteriormente, na Ouvidoria Geral do Estado de São Paulo - que primeiro fizeram florescer o meu interesse por esse assunto, ainda pouco estudado no Brasil, e por isso - bem como por sua inestimável amizade - lhe sou profundamente grato.

Este trabalho reflete também a indelével influência das pessoas com quem tive a sorte de conviver na administração pública paulista, muitas das quais tornaram-se amigas queridas. Agradeço, em especial, a Manuella Ramalho, Fabiana Mentone, Fabiana Nogueira, Renata Martinho, Andrea Oliveira e Ana Lúcia Moreira. Registro também minha sincera gratidão e admiração pelo Dr. Gustavo Ungaro e pela Prof ${ }^{a}$. Dra. Eunice Prudente, cuja incansável dedicação à transparência e à probidade na administração pública tanto me inspiraram ao longo dos últimos anos.

Tive o privilégio de contar ainda com o apoio de muitas amigas e amigos. Tenho uma dívida particularmente grande - diria mesmo impagável - com Paulo Henrique Pereira, Ana Dal Fabbro, Daniel Castro e Thomaz Teodorovicz, amigos de longa data que nos meses finais me emprestaram a energia necessária à conclusão do trabalho.

Sou também extremamente grato pelas sugestões, especialmente bibliográficas, do amigo Thiago Tannous e da Prof ${ }^{a}$ Patricia Jonason, da Universidade de Södertörns, na Suécia, bem como pelos comentários de Maria Isabela Meloncini e Fernanda Rodrigues, amigas e companheiras do Programa de Mestrado.

Não poderia deixar de externar minha honra por contar com a orientação do Prof. Fernando Menezes, verdadeira inspiração acadêmica e pessoal. Faltam-me palavras para agradecer todo o aprendizado que sua convivência me propiciou ao longo dos últimos anos.

Agradeço, por fim, aos meus pais, Denise e Arnolfo, e aos meus irmãos, Maria Luiza, Ricardo e Alexandre - mais valiosos presentes que a vida me deu. 

There is not a crime, there is not a dodge, there is not a trick, there is not a swindle, there is not a vice which does not live by secrecy.

Joseph Pulitzer

Secrecy, once accepted, becomes an addiction.

Atribuído a Edward Teller 



\section{RESUMO}

A visibilidade do poder é um elemento imprescindível a qualquer regime democrático, razão pela qual na democracia a publicidade deve ser a regra, limitando-se o sigilo às excepcionais circunstâncias em que ele é necessário à proteção de interesses legítimos. Entre essas exceções, tem sido pouco estudado o sigilo atribuído às informações custodiadas por empresas estatais sob o argumento da necessidade de resguardar interesses econômicos, tema que ganhou especial relevância após o advento da Lei de Acesso à Informação (Lei 12.527/2011). A presente pesquisa busca identificar as modalidades de sigilo econômico reconhecidas como legítimas na prática da administração pública federal, analisando-as à luz dos parâmetros e diretrizes de acesso à informação propostos por organizações da sociedade civil e organismos internacionais. O objetivo é saber se o tratamento dispensado ao tema na realidade jurídica brasileira é compatível com os critérios internacionais considerados como imprescindíveis à circunscrição do sigilo ao mínimo necessário, de modo a evitar sua indevida expansão sobre o terreno da publicidade. Após apresentar, no Capítulo 2, maiores detalhes sobre a formação e os principais pontos da política legislativa internacional sobre o acesso à informação, os capítulos seguintes comparam a realidade brasileira, a partir de precedentes da Controladoria Geral da União, e os parâmetros internacionais em relação aos seguintes pontos: (i) o grau de vinculação das empresas estatais aos deveres de publicidade decorrentes do direito de acesso à informação; (ii) as modalidades de sigilo econômico reconhecidas como legítimas exceções à regra da publicidade; e (iii) os arranjos institucionais e jurídicos voltados a induzir a limitação da aplicação do sigilo aos casos concretos. O estudo dessas questões indica a existência de ao menos quatro modalidades de sigilo econômico - sigilo concorrencial, sigilo das companhias abertas, sigilo contratual e sigilo escritural -, as quais, no entanto, carecem de disciplina legal adequada, bem como de regramento processual que assegure a limitação dessas hipóteses ao mínimo necessário para a preservação dos interesses econômicos da administração pública. Conclui-se, ao final, que embora a lei brasileira apresente um elevado grau de aderência aos parâmetros internacionais, o tratamento dispensado ao sigilo econômico é disfuncional, comportando aprimoramentos.

Palavras-chave: Direito de Acesso à Informação. Empresas Estatais. Transparência. Sigilo Comercial. Sigilo Econômico. 



\begin{abstract}
Transparency of power is an indispensable trait of any democracy, which means publicity ought to be the rule and secrecy should be limited to the exceptional circumstances in which it is necessary to protect legitimate interests. Among these exceptions, not much attention has been given to the confidentiality of information held by state-owned enterprises under the pretext of safeguarding economic interests, a topic especially relevant since the Brazilian Freedom of Information Act (Law n. 12.527/2011) came into force. This research aims at identifying the species of economic secrecy regarded as legitimate in the federal public administration, in light of the international standards on freedom of information defined by civil society organizations and international agencies. The purpose is to find out whether the treatment of that topic in Brazilian Law is compatible with the international criteria, which are considered necessary to circumscribe secrecy to the bare minimum, in order to prevent undue expansion over the territory of transparency. After presenting in further details the development and main aspects of the international legislative policy on access to information (chapter 2), the following chapters compare the Brazilian reality and the international standards, regarding the following topics: (i) the degree to which state-owned enterprises are bound by the disclosure obligations related to right to information law; (ii) the kinds of economic secrecy regarded as legitimate exceptions to the rule of publicity; and (iii) the institutional and legal design aimed at discouraging the excessive application of secrecy in concrete scenarios. The analysis points to the existence of at least four kinds of economic secrecy competition secrecy, secrecy of listed companies, contractual secrecy and records secrecy -, which, however, lack the adequate legal discipline, as well as procedures able to vouch for its limitation to the bare minimum indispensable to preserve the economic interests of the public administration. Thus, it is possible to conclude that, although the Brazilian FOIA presents substantive adherence to the international standards, its regulation of economic secrecy is dysfunctional.
\end{abstract}

Keywords: Right to Information. State-owned Enterprises. Trade Secrets. Economic Secrecy. Transparency. 



\section{SUMÁRIO}

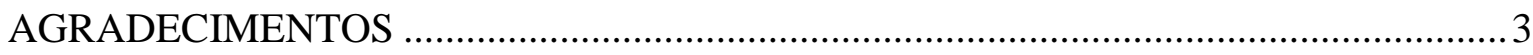

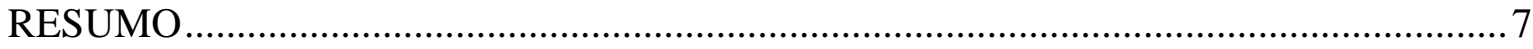

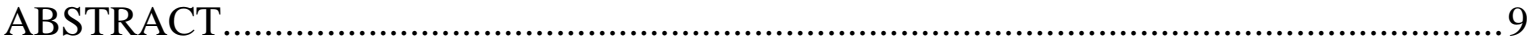

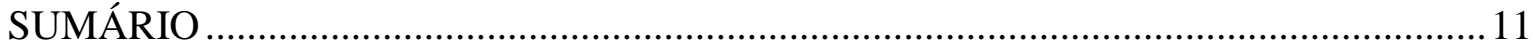

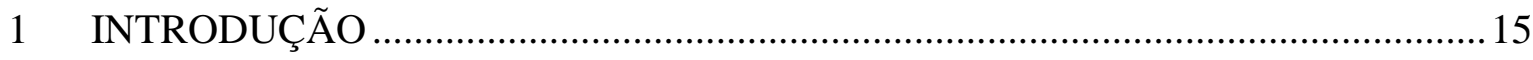

1.1 CONSIDERAÇÕES GERAIS: CONTEXTO, HIPÓTESE E OBJETO .............. 15

1.2 CONSIDERAÇÕES TERMINOLÓGICAS E CONCEITUAIS .........................21

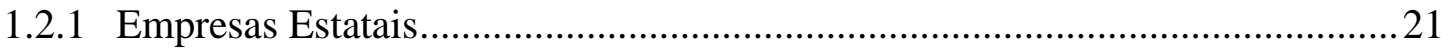

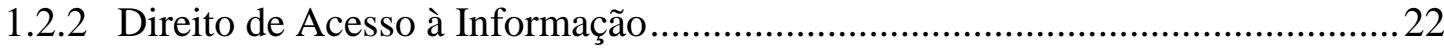

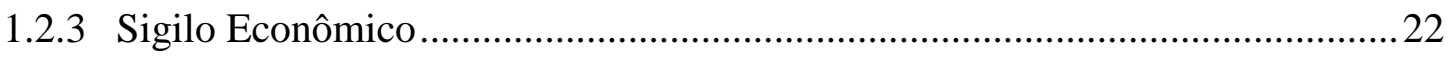

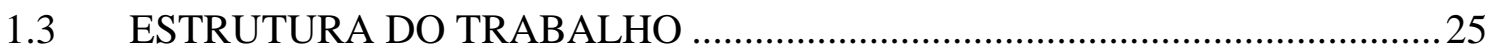

2 A POLÍTICA LEGISLATIVA INTERNACIONAL SOBRE ACESSO À

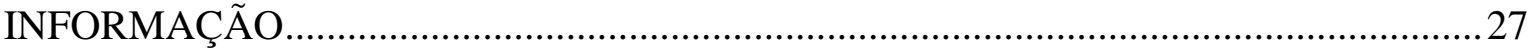

2.1 A CONSTRUÇÃO DA POLÍTICA LEGISLATIVA INTERNACIONAL

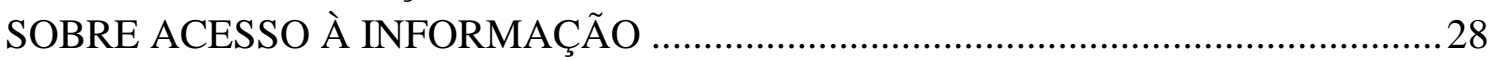

2.1.1 A difusão das leis de acesso à informação .........................................................2 28

2.1.2 A atribuição de um conteúdo mínimo às normas de acesso à informação ........34

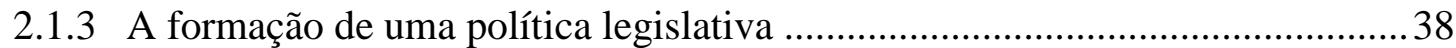

2.2 PRINCÍPIO DA MÁXIMA DIVULGAÇÃO: PEDRA ANGULAR DO

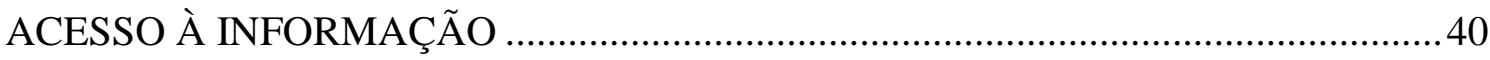

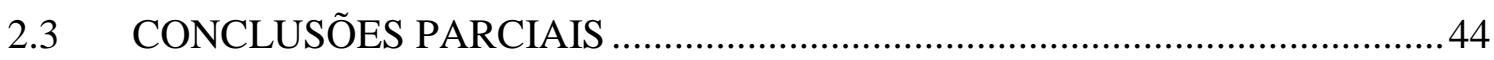

3 A SUJEIÇÃO DAS EMPRESAS ESTATAIS AO DIREITO DE ACESSO À INFORMAÇÃO

3.1 A EXTENSÃO SUBJETIVA DAS NORMAS DE ACESSO À INFORMAÇÃO NO PLANO INTERNACIONAL

3.1.1 O alcance das normas de acesso à informação de acordo com a política legislativa internacional

3.1.2 O alcance das normas de acesso à informação na prática legislativa internacional.

3.2 A EXTENSÃO SUBJETIVA DAS NORMAS DE ACESSO À INFORMAÇÃO NO BRASIL 52

3.2.1 A extensão subjetiva da Lei de Acesso à Informação.......................................52

3.2.2 A sujeição das empresas estatais à lei de acesso à informação..........................56 
3.2.2.1 Delimitação do problema .56

3.2.2.2 As empresas estatais que exploram atividade econômica em regime de concorrência 60

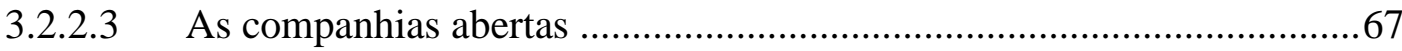

3.2.2.4 A posição da Controladoria Geral da União...........................................70

3.2.2.5 O Estatuto Jurídico das Empresas Estatais (Lei 13.303/2016) ...............77

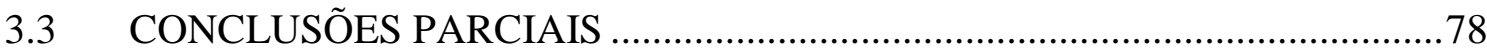

4 AS HIPÓTESES DE SIGILO ECONÔMICO APLICÁVEIS ÀS EMPRESAS

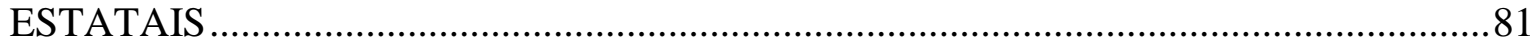

4.1 AS EXCEÇÕES À REGRA GERAL DE PUBLICIDADE NA POLÍTICA

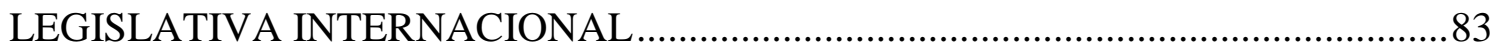

4.1.1 Os interesses tutelados pelo sigilo e sua legitimidade ….................................84

4.1.1.1 "Sigilo-privacidade" e "sigilo-instrumento": uma diferenciação ...........85

4.1.2 A necessidade de previsão expressa em lei .....................................................90

4.1.3 O exame da proporcionalidade do sigilo.........................................................91

4.2 AS EXCEÇÕES À REGRA GERAL DE PUBLICIDADE NO DIREITO

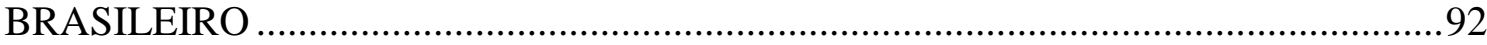

4.2.1 As hipóteses de restrição de acesso previstas na Lei de Acesso à Informação.93

4.2.2 Sigilo econômico na administração pública federal.........................................98

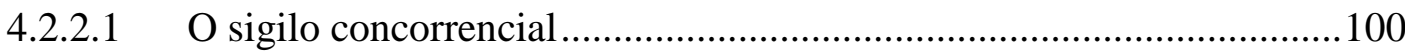

4.2.2.1.1 Exemplos de aplicação do sigilo concorrencial pela CGU ..............100

4.2.2.1.2 Fundamento legal do sigilo concorrencial......................................106

4.2.2.1.3 Quem pode invocar o sigilo concorrencial? ...................................121

4.2.2.2 Sigilo das Companhias Abertas ..........................................................128

4.2.2.2.1 A interpretação do artigo 155 da Lei das Sociedades Anônimas .....128

4.2.2.2.2 O sigilo como proteção do mercado de capitais ...............................133

4.2.2.2.3 Os requisitos do sigilo das companhias abertas .............................136

4.2.2.2.4 As diferenças entre sigilo concorrencial e sigilo das companhias aberta 138

4.2.2.2.5 O sigilo das companhias abertas nas decisões da Controladoria Geral da União 139

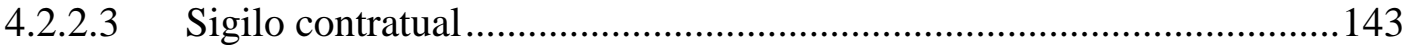

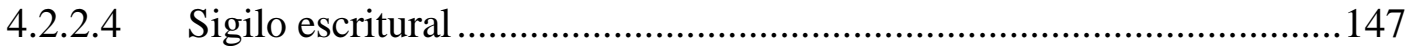

4.2.3 Síntese das modalidades de sigilo econômico ..................................................149

4.2.4 A informação como objeto de exploração econômica ....................................152 
4.2.5 A aplicação do sigilo econômico à luz das diretrizes internacionais .

4.3 CONCLUSÕES PARCIAIS

5 SIGILO COMO DECISÃO: ELEMENTOS CONFORMADORES DA DISCRICIONARIEDADE*

5.1 POLÍTICA LEGISLATIVA INTERNACIONAL: A CONFORMAÇÃO DA

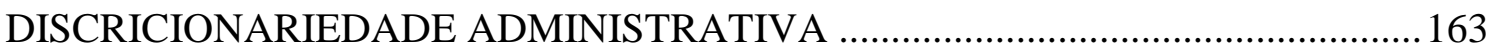

5.1.1 O sigilo como decisão 163

5.1.2 Os elementos conformadores da discricionariedade na política legislativa internacional. 165

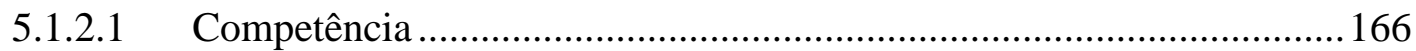

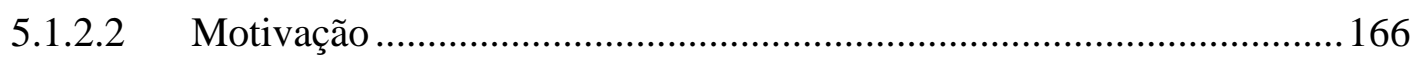

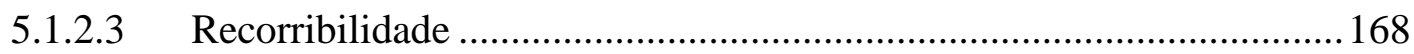

5.1.2.4 Limitação temporal do segredo ...................................................... 170

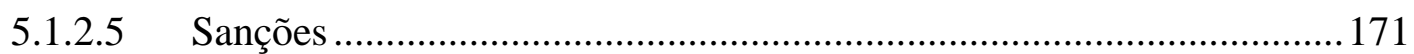

5.2 SIGILO COMO DECISÃO E A CONFORMAÇÃO DA DISCRICIONARIEDADE NO DIREITO BRASILEIRO ...................................... 173

5.2.1 Os procedimentos de acesso à informação e de classificação na Lei de Acesso à Informação

5.2.2 Elementos conformadores da discricionariedade no procedimento de classificação 177

5.2.3 Elementos conformadores da discricionariedade no procedimento de acesso à informação 184

5.2.4 A conformação da discricionariedade no sigilo econômico 187

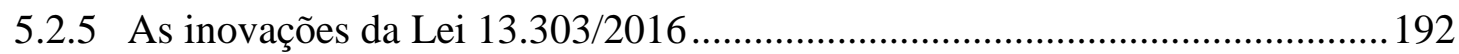

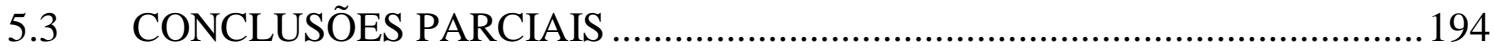

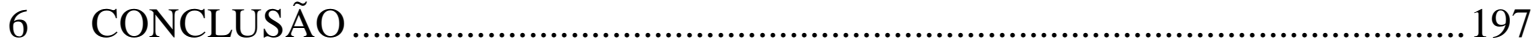

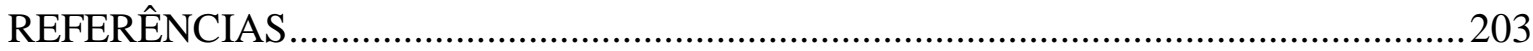

APÊNDICE - RECURSOS DE ACESSO À INFORMAÇÃO SELECIONADOS PARA ANÁLISE DO SIGILO ECONÔMICO 



\section{INTRODUÇÃO}

\subsection{CONSIDERAÇÕES GERAIS: CONTEXTO, HIPÓTESE E OBJETO}

A publicidade é um conceito extremamente caro à democracia. Se o poder democrático está, por definição, constantemente sujeito ao escrutínio popular, é fundamental que seja exercido em público, às claras, municiando assim os cidadãos das informações necessárias ao controle das atividades estatais e à formação de suas convicções políticas. Não é por menos que Norberto BOBBIO, utilizando-se de um jogo de palavras, chegou a definir o governo democrático como "o governo do poder público em público"1.

Ainda que esse vínculo entre democracia e publicidade remonte à Grécia Antiga, tal relação passou por grandes transformações ao longo da história. Em linhas gerais, pode-se afirmar que, ao menos nas democracias ocidentais, o conceito de publicidade expandiu-se paulatinamente, transbordando da mera visibilidade dos atos normativos para abranger também os processos anteriores de deliberação e formação desses mesmos atos, bem como a identificação e controle dos resultados produzidos. Da publicidade, portanto, passou-se à transparência, noção mais ampla que aquela por trazer consigo as ideias de motivação, participação popular e controle social ${ }^{2}$.

Um dos produtos da transformação da ideia de publicidade é o crescente reconhecimento do chamado direito de acesso à informação, que pode ser genericamente definido como o direito subjetivo que pode ser invocado para ter acesso a informações de interesse particular ou geral custodiadas por entidades integrantes da administração pública. Já em 1766 a Suécia disciplinava o acesso a registros públicos, mas foi somente na segunda metade do século XX que o direito de acesso à informação passou a ser reconhecido internacional enquanto direito autônomo, processo ainda em desdobramento.

No Brasil, ainda que a Constituição Federal de 1988 já assegurasse, em seu artigo $5^{\circ}$, XXXIII, o "direito a receber dos órgãos públicos informações de seu interesse particular, ou de interesse coletivo ou geral”, o tema ganhou especial destaque a partir da

\footnotetext{
1 O Futuro da Democracia: uma defesa das regras do jogo. Tradução de Marco Aurélio Nogueira. $10^{\mathrm{a}}$ ed. São Paulo: Paz e Terra, 2006, p. 98.

2 MARTINS JUNIOR, Wallace Paiva. Princípio da Transparência. In: DI PIETRO, Maria Sylvia Zanella (coord.). Tratado de direito administrativo, v.1. São Paulo: Thomson Reuters Revista dos Tribunais, 2015, pp. 420 e ss.
} 
edição da Lei 12.527, de 18 de novembro de 2011, a chamada Lei de Acesso à Informação (LAI), que buscou regulamentar o dispositivo constitucional de acordo com as melhores práticas internacionais. $\mathrm{O}$ novo texto legal fez recrudescer junto à sociedade o coro por maior transparência e controle social da administração pública, e diversos estudos passaram a se debruçar sobre o direito de acesso à informação, seja para identificar desafios em sua implantação, seja para mensurar seu impacto nas práticas administrativas ${ }^{3}$.

Uma das questões que tem recebido crescente atenção é a necessidade de equacionamento entre publicidade e sigilo. Porque se a publicidade é ou deve ser a regra geral em regimes democráticos, há situações específicas nas quais o interesse da sociedade exige a restrição do acesso às informações custodiadas pelo Poder Público, ora para garantir a efetividade da ação estatal, ora para proteger a intimidade ou a segurança de seus cidadãos. O desafio consiste exatamente em reconhecer a existência e a necessidade da restrição de acesso nesses cenários e, ao mesmo tempo, assegurar que tais restrições se limitem às situações excepcionais que a justificam.

Entre as diversas modalidades de sigilo que podem existir, pouca atenção tem sido dada à necessidade de proteção das informações em posse de empresas controladas pelo poder público. Entidades "híbridas", as empresas estatais congregam interesses públicos e privados, na medida em que, integrando a administração pública indireta, organizam-se pela lógica do mercado, contando inclusive, no caso das sociedades de economia mista, com participação acionária de particulares. Além de contemplar interesses múltiplos, as estatais atuam com frequência em mercados competitivos, nos quais a informação desempenha um papel estratégico para o sucesso da companhia. Nesse contexto, a aplicação dos critérios que orientam a relação entre publicidade e sigilo nas demais áreas da administração pública enfrenta uma série de dificuldades.

Ao mesmo tempo, a sociedade tem bons motivos para exigir ampla transparência nas empresas estatais, uma vez que estas, tanto quanto a administração direta, desempenham papel relevante na persecução das finalidades eleitas pelo governo, ora servindo como instrumento de intervenção do Estado na economia, ora atuando diretamente na realização de políticas públicas. Nesse contexto, a transparência administrativa contribui para a avaliação dos resultados da ação estatal, bem como para mitigar os riscos da corrupção e da malversação de recursos.

3 Cf., por todos, as pesquisas desenvolvidas no âmbito do Programa de Transparência Pública da Fundação Getúlio Vargas, coordenada pelo Professor Gregory Michener. Parte do material produzido encontra-se disponível no portal <http://transparencia.ebape.fgv.br/>. 
Nas empresas estatais, portanto, nota-se uma tensão entre o interesse da companhia na preservação de certas informações consideradas estratégicas e o interesse público na transparência, pressuposto do controle social e democrático.

A perplexidade provocada por essas tendências contraditórias não se restringe ao plano conceitual, projetando diversos efeitos sobre a prática administrativa cotidiana, como bem exemplifica o caso brasileiro. O jornalista que questiona a SABESP sobre ações promovidas durante a crise hídrica; o cidadão que solicita cópia dos contratos celebrados pela Petrobrás; a startup que pede acesso às bases de dados detidas pelo Metrô; o acadêmico que requer as notas fiscais das compras realizadas pelo Banco do Brasil; todos os dias, casos como esses ensejam decisões, explícitas ou tácitas, negando ou franqueando acesso às informações custodiadas por empresas estatais.

É com esse pano de fundo que se desenvolve o presente trabalho, cujo objetivo é estudar a proteção à confidencialidade das informações custodiadas por empresas estatais à luz do direito brasileiro e das diretrizes internacionais sobre o tema. Mais especificamente, investiga-se a hipótese de que o tratamento dispensado pela administração pública federal às modalidades de sigilo voltadas à proteção dos interesses econômicos das empresas estatais encontra-se em desacordo com os parâmetros internacionais de direito de acesso à informação.

Assim, propõe-se o contraste entre dois planos distintos: de um lado, a realidade jurídica brasileira; de outro, as diretrizes internacionais. Cabe delimitar com maior precisão cada um desses planos, a começar pelo segundo.

A partir da década de 1990, em um processo que será melhor explicado no primeiro capítulo, diversas organizações da sociedade civil e, posteriormente, organismos internacionais empreenderam esforços na delimitação de um conteúdo mínimo que toda legislação de acesso à informação deveria apresentar, com vistas a criar as condições necessárias para o exercício adequado do direito de acesso. Esse conteúdo mínimo tem sido frequentemente articulado sob a forma de "princípios" do direito de acesso à informação, apresentados em diversos documentos publicados ao longo dos últimos vinte anos, os quais não possuem valor normativo próprio, mas que pretendem influenciar os legisladores nacionais na confecção de textos normativos locais. Sustento que esse esforço, que envolveu um número crescente de atores, resultou na formação de uma política legislativa internacional, buscando pressionar os legisladores nacionais a adotar um conjunto de regras, arranjos e mecanismos jurídico-institucionais voltados a assegurar a 
efetividade do direito de acesso à informação. É esse conjunto de proposições que, para os fins deste trabalho, constituem os parâmetros ou diretrizes internacionais sobre acesso à informação ${ }^{4}$.

Para delinear os principais contornos dessa política legislativa internacional, analiso ao longo do trabalho dez documentos elaborados por organizações da sociedade civil ou por organismos internacionais, publicados entre os anos de 1995 e 2013 com o propósito expresso de influenciar a confecção de normas de acesso à informação ${ }^{5}$. Os dez documentos serão apresentados em maiores detalhes no primeiro capítulo, mas importa frisar que a seleção dos documentos foi feita com base em três critérios principais.

Em primeiro lugar, somente foram selecionados documentos elaborados por instituições ou grupos de reconhecida expressão internacional na trajetória do direito de acesso à informação. Diversas das publicações, aliás, são subscritas por uma coalização de entidades atuantes na área, demonstrando com isso a coesão e a abrangência que os parâmetros internacionais pretendem alcançar. Assim, não foram incluídos materiais de autoria individual, mesmo que coerentes com o teor dos documentos internacionais e independentemente do mérito de seus autores ${ }^{6}$.

Em segundo lugar, todos os documentos analisados têm o nítido propósito de influenciar a confecção de legislações nacionais. Alguns deles, é claro, vão além disso, seja por englobarem também outros direitos - como a liberdade de expressão -, seja por defenderem pontos que transcendem a questão legislativa - como a capacitação de servidores públicos -, seja por não se destinarem exclusivamente aos Estados. Nesse sentido, ficaram de fora outros documentos que se limitam às organizações internacionais

4 Evito referir-me a essas proposições como "princípios" do direito de acesso à informação, embora essa seja a opção terminológica da maior parte dos documentos internacionais sobre o assunto. Isso porque, no direito brasileiro, o vocábulo princípio já possui uma elevada carga semântica que tem suscitado grandes controvérsias, sobretudo na teoria do direito constitucional. Ao optar por "diretrizes" ou "parâmetros", busco enfatizar que os documentos internacionais não são capazes de atribuir valor normativo a essas proposições, o que não significa que o direito brasileiro (ou outras legislações, nacionais e internacionais) não possa, com fundamentos autônomos, conferir-lhes status jurídico.

5 Parte dos documentos internacionais, bem como da literatura acadêmica a seu respeito, foi redigida apenas em inglês ou espanhol. Para manter maior fidelidade aos textos originais, optei por fazer-lhe referência no idioma original, sem traduções para o português. Tendo em vista a difusão desses dois idiomas no meio acadêmico, acredito que a escolha não trará prejuízos para a compreensão do trabalho.

6 Isso não significa que esses materiais não subsidiarão a análise, mas apenas que não terão o mesmo tratamento dispensado aos documentos internacionais. Um bom exemplo de documento individual que, em outro contexto, poderia ter sido incluído é o working paper "Designing Right to Information Laws for Effective Implementation", elaborado por Toby MENDEL, autor de indisputada relevância no tema do acesso à informação, ex-diretor do Programa de Direito da ONG britânica Artigo 19 e atual presidente da International Freedom of Information Advocates Network (FOIAnet). Também não incluí os "10 Princípios para um Governo Aberto Efetivo", elaborados pelos professores Irène Bouhadana e William Gilles, da Faculdade de Direito de Sorbonne. 
ou que sejam meramente descritivos, sem a pretensão de influenciar a confecção de novas normas ${ }^{7}$.

Por fim, o último critério de seleção dos documentos internacionais foi a repercussão gerada. Ainda que não seja possível precisar o impacto de cada documento, aqueles de maior importância podem ser identificados a partir de diversos indícios, como (i) número de adesões, (ii) citações por documentos posteriores, (iii) menções por parte de textos acadêmicos e normativos, (iv) endosso institucional por parte de organizações internacionais.

Ao mesmo tempo em que se debruça sobre a política legislativa internacional, o presente trabalho volta-se para a realidade jurídica brasileira, mais especificamente para o tratamento conferido ao direito de acesso à informação nas empresas estatais vinculadas ao governo federal. Para esse fim, o principal material de análise serão as decisões da Controladoria Geral da União (CGU), à qual compete o julgamento dos recursos interpostos contra órgãos e entidades da administração pública federal, no curso do procedimento de acesso à informação disciplinado pela $\mathrm{LAI}^{8}$.

O acervo decisório da CGU é uma fonte privilegiada para o estudo de casos concretos, uma vez que o órgão federal é provocado a manifestar-se cotidianamente sobre o tema do acesso à informação. Entre maio de 2012, quando a LAI entrou em vigor, e julho de 2017, a CGU já julgou mais de 6.300 recursos administrativos relativos a pedidos de acesso à informação, sendo que todas as decisões se encontram disponíveis na internet ${ }^{9}$. Ademais, a existência de um escopo específico compartilhado por todas as decisões disponibilização ou não da informação requerida -, favorece enormemente a comparação entre as motivações de cada juízo recursal. Outro ponto relevante é o fato de que, por se tratar de um único órgão, há um sensível esforço de padronização das interpretações adotadas, o que contribui para a sistematização de entendimentos.

A CGU não apenas julga os recursos que lhe são dirigidos, como também desempenha um papel de orientação e fiscalização dos demais órgãos e entidades da

\footnotetext{
7 Um bom exemplo é a Carta de Transparência para Instituições Financeiras Internacionais (“Transparency Charter for International Financial Institutions: Claiming our Right to Know"), elaborada pela Global Transparency Initiative, que traz nove princípios sobre acesso à informação. O foco exclusivo nas instituições financeiras internacionais, não obstante haja uma significativa convergência principiológica, justifica sua exclusão do rol de documentos considerados para os fins desta pesquisa.

8 Em 2016, a Controladoria Geral da União teve seu nome alterado para Ministério da Transparência e Controladoria-Geral da União $(C G U)$. Considerando que grande parte das fontes analisadas são anteriores à nova designação, optei por referir-me apenas à Controladoria Geral da União, de modo a manter uma coerência terminológica ao longo de todo o trabalho.

9 As decisões, bem como informações estatísticas sobre pedidos e recursos, estão disponíveis no endereço <http://www.acessoainformacao.gov.br>.
} 
administração pública federal. Nesse sentido, ainda que haja divergências entre estes e a CGU, a tendência de longo prazo, no tocante ao acesso à informação, é a consolidação da prática administrativa no sentido dos entendimentos esposados pelo órgão recursal.

Cabe ressaltar que a CGU não é a última instância recursal no procedimento de acesso à informação, uma vez que, acima dela, há a Comissão Mista de Reavaliação de Informações (CMRI), um órgão colegiado composto por representantes de diferentes ministérios. As decisões da CMRI também serão objeto de análise na presente dissertação; no entanto, somente serão feitas menções esporádicas aos seus entendimentos, por três motivos. Primeiramente, porque as decisões do órgão colegiado são demasiado sintéticas, não permitindo a compreensão completa do raciocínio que conduziu àquela conclusão, ao passo que as decisões da CGU, por seu turno, possuem detalhada fundamentação. Segundo, são raríssimas as ocasiões em que a CMRI reforma as decisões da CGU; na realidade, entre maio de 2012 e julho de 2017, a comissão julgou 1.661 recursos, dos quais apenas 18 foram providos, total ou parcialmente, o que corresponde a um índice de 1,08\%. Por fim, em razão da relação hierárquica entre as instâncias, os entendimentos da CMRI são rapidamente incorporados às decisões da CGU, de modo que há uma clara tendência de convergência entre as duas instâncias ${ }^{10}$.

Por esses motivos, o acervo de decisões recursais da CGU pode ser considerado como representativo da postura da administração pública federal em relação ao direito de acesso à informação, embora persista a possibilidade de as empresas estatais adotarem posturas divergentes na apreciação de pedidos concretos, os quais muitas vezes não chegam às instâncias recursais.

Para a elaboração do presente trabalho foram analisadas 963 decisões proferidas pela Controladoria Geral da União entre maio de 2012 e fevereiro de 2017 em recursos de acesso à informação interpostos contra 49 empresas estatais federais. Desse conjunto, foram identificados 380 casos, envolvendo 27 empresas (ver Apêndice), nos quais o acesso

10 Leonardo BENTO (Acesso a Informações Públicas: princípios internacionais e o direito brasileiro. Curitiba: Juruá, 2015, p. 207), criticando o arranjo institucional adotado pelo Decreto 7.724/2012, ressalta o papel preponderante da CGU no contexto recursal: "Convém salientar, ainda, que a CGU, além de ser ela própria uma instância recursal (...), também é membro da Comissão de Reavaliação (...). Noutras palavras, o órgão recorrido profere voto no julgamento do recurso interposto contra sua própria decisão (!). Trata-se de uma situação esdrúxula que, somada à baixíssima taxa de sucesso dos recursos, permite inferir que a CGU, por ser o órgão com maior conhecimento técnico da temática da transparência e do acesso à informação, exerce uma ascendência natural sobre os demais membros da CMRI, os quais se limitam a acatar seus argumentos". 
às informações solicitadas foi indeferido, entre outros argumentos, sob alegação da existência de sigilo econômico ${ }^{11}$.

A pesquisa também será subsidiada por decisões judiciais. Até o momento, porém, estas se revelam fonte bastante limitada para o objeto da presente dissertação, em razão (i) do número relativamente baixo de decisões sobre o tema do direito de acesso à informação nas empresas estatais - em especial desde o advento da LAI -, as quais (ii) encontram-se dispersas por vários tribunais, com poucos pronunciamentos dos tribunais superiores. Ambos os fatores se colocam como obstáculos à consolidação de entendimentos, o que dificulta a identificação de padrões decisórios relevantes.

O objetivo do presente trabalho, portanto, é analisar - principalmente a partir das decisões recursais da Controladoria Geral da União - o tratamento jurídico que a administração pública federal tem dispensado ao tema do sigilo nas empresas estatais à luz dos parâmetros internacionais sobre o assunto, com vistas a verificar possíveis convergências ou incompatibilidades.

\subsection{CONSIDERAÇÕES TERMINOLÓGICAS E CONCEITUAIS}

\subsubsection{Empresas Estatais}

A expressão "empresas estatais" não se refere a um conjunto homogêneo de instituições, tratando-se antes de categoria que reúne tipos diversos de organizações societárias. Para os fins da presente pesquisa, em consonância com a sistemática legal sobre o assunto, serão consideradas empresas estatais (i) as sociedades de economia mista, compreendidas como as sociedades anônimas cujas ações com direito a voto pertençam em sua maioria a algum ente público, contando também com participação acionária privada; (ii) as empresas públicas, cujo quadro societário é composto apenas por pessoas de direito

11 Os julgamentos referem-se a um total de 1382 recursos, o que se explica pelo fato de que, em muitas situações, uma mesma decisão reúne diversos protocolos. Ao longo da dissertação, as citações aos recursos observarão o seguinte padrão: (i) número da manifestação (despacho, parecer ou nota técnica) da CGU, o qual permite identificar o documento que fundamentou a decisão do órgão recursal; (ii) Número Único de Protocolo (NUP), o qual é atribuído ao pedido de acesso à informação no momento de sua formulação, sendo utilizado como referência até o encerramento da demanda; (iii) órgão ou entidade contra quem se dirigiu o recurso. Excepcionalmente, serão citadas manifestações das empresas estatais em pedidos de acesso que não foram objeto de recurso à CGU; nesses casos, será identificado apenas o NUP correspondente ao pedido. Todas decisões recursais encontram-se disponíveis no portal < http://www.acesso ainformacao.gov.br/>. 
público; e (iii) empresas controladas indiretamente por sujeito estatal (subsidiárias) ${ }^{12}$. Por outro lado, a categoria deixa de abranger as empresas privadas em que o poder público detém participação minoritária ou as “empresas público-privadas", também chamadas semiestatais ${ }^{13}$.

\subsubsection{Direito de Acesso à Informação}

O vocábulo "direito" pode assumir múltiplos significados, a depender do contexto em que está inserido. Embora o termo comporte ainda outros sentidos, é comum que se faça a distinção entre direito objetivo e direito subjetivo, referindo-se o primeiro a um conjunto de normas válidas (tal qual na expressão "o direito brasileiro não admite a repristinação tácita"), enquanto o segundo consistiria na faculdade subjetiva - reflexo do direito objetivo - que permite ao indivíduo exigir certo comportamento alheio (como quando dizemos que o credor tem direito de receber determinada quantia do devedor).

No âmbito da presente dissertação, procuro limitar o uso da expressão "direito de acesso à informação" para me referir ao direito subjetivo que habilita o seu titular a exigir acesso aos dados e documentos custodiados por órgãos e entidades da administração pública. Para descrever as regras que visam a proteger e assegurar esse direito subjetivo, utilizo-me preferencialmente da locução "normas de acesso à informação".

\subsubsection{Sigilo Econômico}

As informações cuja divulgação é condicionada, ou mesmo vedada, pelo ordenamento jurídico são recorrentemente descritas como reservadas, confidenciais, secretas, sigilosas ou de acesso restrito. Embora esses termos e expressões sejam utilizados com frequência de forma intercambiável, a Lei n. 12.527/2011 (Lei de Acesso à Informação - LAI) atribui-lhes significados específicos, começando pela distinção entre gênero e espécie. A categoria mais ampla, abrangendo todas as demais, é a das informações de acesso restrito. Nela estão incluídas todas as informações custodiadas pela

12 As três categorias encontram respaldo legal tanto no Decreto-lei 200, de 25 de fevereiro de 1967, quanto na Lei 13.303, de 30 de junho de 2016, bem como na própria Constituição Federal.

13 Rafael Wallbach SCHWIND (Participação estatal em empresas privadas: as "empresas públicoprivadas". Tese de Doutorado. Faculdade de Direito, Universidade de São Paulo, São Paulo, 2014) define empresas público-privadas como "sociedades comerciais privadas, não integrantes da Administração Pública, em que o Estado, por meio de um ente estatal, participa como sócio e se vale de instrumentos societários destinados a direcionar o comportamento da empresa para a realização de determinados objetivos públicos previstos no ordenamento jurídico, mas sem possuir, de modo permanente, preponderância no exercício do poder de controle" 
administração pública e que, por algum motivo, não podem ser disponibilizadas livremente a qualquer interessado, exigindo uma qualificação subjetiva para seu acesso.

A LAI, lastreada no artigo $5^{\circ}$, inciso XIII da Constituição, disciplina duas espécies principais de informações de acesso restrito: as informações pessoais e as informações sigilosas. As primeiras relacionam-se à intimidade, vida privada, honra e imagem da pessoa natural identificada ou identificável (arts. $4^{\circ}$, inc. IV, e 31). Em regra, o acesso a esses dados é restrito a "agentes públicos legalmente autorizados e à pessoa a que elas se referirem" (art. $\left.31, \S 1^{\circ}\right)$. Já a informação sigilosa é "aquela submetida temporariamente à restrição de acesso público em razão de sua imprescindibilidade para a segurança da sociedade e do Estado" (art. $4^{\circ}$, inc. III), subdividindo-se, conforme a duração do sigilo, em reservada (até cinco anos), secreta (até quinze anos) ou ultrassecreta (até vinte e cinco anos).

No restante da legislação, não se observa o mesmo rigor terminológico, sendo que os textos legais utilizam indiscriminadamente termos como segredo, sigilo, confidencialidade, entre outros.

No campo da proteção às informações empresariais, a legislação faz uso de diversas expressões: segredos de negócios, segredos de fábrica, segredo industrial, sigilo empresarial, sigilo comercial, sigilo estratégico, sigilo de operações e serviços no mercado de capitais, informações confidenciais, entre outros. No mais das vezes, a legislação não traz uma delimitação clara dessas hipóteses, tampouco indica quais as diferenças entre cada uma delas. Assim, para evitar confusões decorrentes da carga semântica que cada uma dessas nomenclaturas traz, opto por uma expressão que não consta em textos legislativos brasileiros: "sigilo econômico". No âmbito deste trabalho, portanto, essa locução deve ser entendida como a categoria dentro da qual se insere o conjunto de hipóteses de restrição de acesso que têm por fundamento a defesa de interesses econômicos da empresa estatal.

Cabe registrar ainda que, para os fins da pesquisa, não se inclui entre as hipóteses de sigilo econômico aquela prevista na Lei Complementar n. 105, de 10 de janeiro de 2001, que dispõe sobre o sigilo das operações de instituições financeiras, também conhecido como sigilo bancário. Isso porque, embora a restrição de acesso ocorra no âmbito de operações econômicas, a sua finalidade não é a proteção dos interesses comerciais da empresa, mas antes a garantia da inviolabilidade da intimidade e da vida 
privada do indivíduo ${ }^{14}$. Em outras palavras, o sigilo bancário pode ser qualificado como desdobramento da restrição de acesso às informações pessoais, hipótese legal que foge ao escopo do presente trabalho.

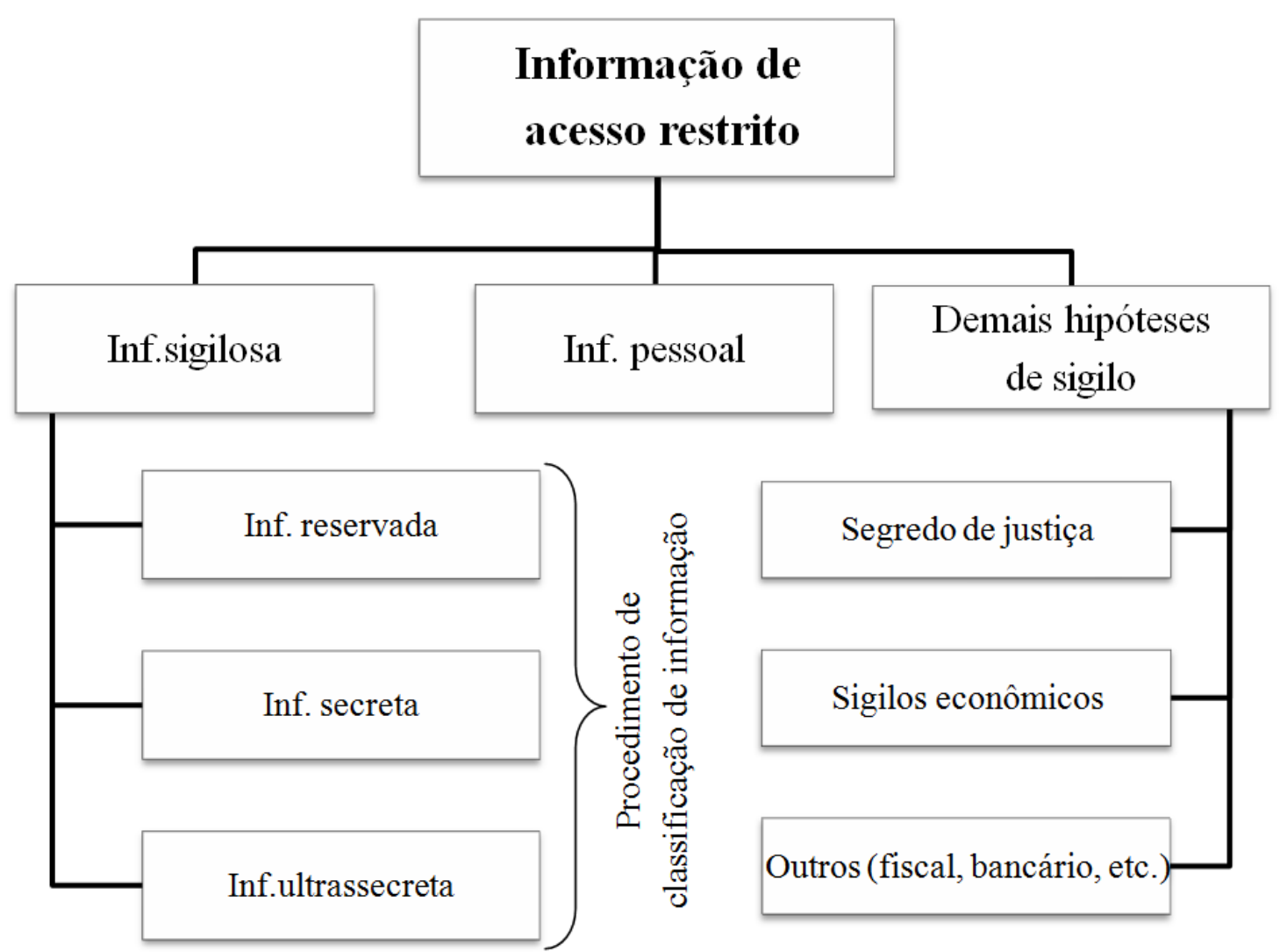

Figura 1 - Hipóteses de restrição de acesso na Lei de Acesso à Informação.

Também não se inclui no escopo do presente trabalho o problema do acesso às informações de empresas privadas que, por qualquer motivo, encontram-se em posse do Estado. A proteção às informações empresariais privadas mereceria pesquisa própria, a uma pela extensão do tópico e, a duas, pelas questões específicas que esse problema suscita. Assim, o estudo do sigilo econômico está limitado às empresas estatais.

14 Não poderia ser mais cristalino a esse respeito o parecer aprovado pela Comissão de Constituição e Justiça da Câmara dos Deputados, quando da análise do projeto que resultou na LC 105/2011: "Atualmente, prevalece o entendimento que o segredo bancário é instrumento que possibilita o exercício do direito à privacidade, um atributo dos direitos da personalidade, no campo das operações econômicas. Ineludível que o sigilo garante ao cidadão a possibilidade de manter a indevassabilidade de informações que venham a expor a sua privacidade. A inviolabilidade de dados é o instrumento que permite a existência da vida privada e da intimidade, afastando a discricionariedade e o arbítrio de autoridades e de terceiros, que somente podem conhecer certas situações nos casos legalmente previstos mediante a instauração do devido processo legal. É nesse contexto que a matéria se situa no Direito Constitucional pátrio. A Carta Política de 88 , no art. $5^{\circ}$, incisos X e XII, consagra como direitos fundamentais a inviolabilidade da intimidade e da vida privada, bem como o sigilo de dados. $\mathrm{O}$ sigilo de dados a que se refere o texto constitucional é espécie do gênero segredo profissional, o que abarca o chamado sigilo bancário. É, hoje, pacífico o entendimento esposado inicialmente pelo Superior Tribunal de Justiça de que o sigilo bancário constitui espécie de direito à intimidade". (Autor: Dep. Ney Lopes, publicado no Diário Oficial da Câmara em 03 de agosto de 2000). 


\subsection{ESTRUTURA DO TRABALHO}

A presente dissertação divide-se em quatro capítulos, além desta introdução e da conclusão. O Capítulo 2 (o primeiro após a introdução) expõe, em maiores detalhes, o que se entende por política legislativa internacional do direito de acesso à informação e os seus principais pontos. Os capítulos seguintes abordam aspectos distintos do problema central da pesquisa, qual seja a relação entre sigilo econômico e direito de acesso à informação no âmbito das empresas estatais.

No Capítulo 3, procura-se delimitar com maior precisão como se dá a sujeição das empresas estatais às normas de acesso à informação. Em outras palavras, cuida-se de saber se e em que medida as empresas estatais estão obrigadas a disponibilizar seus dados e documentos como decorrência do direito de acesso à informação. O Capítulo 4, por sua vez, investiga as hipóteses que justificariam a restrição de acesso às informações custodiadas por empresas estatais, com vistas a preservar interesse econômico. Por fim, o Capítulo 5 volta-se para os elementos procedimentais que conformam a decisão administrativa que aplica o sigilo ao caso concreto; trata-se, em outras palavras, de identificar os instrumentos utilizados para limitar a discricionariedade do agente público na aplicação do sigilo.

Esses três capítulos apresentam uma estrutura similar. Todos iniciam pela análise da política legislativa internacional, buscando extrair as diretrizes propostas sobre o tema específico de cada capítulo. Uma vez apresentado o cenário internacional, passa-se à análise do direito brasileiro, com especial atenção à atuação da Controladoria Geral da União nos casos concretos. 


\section{CONCLUSÃO}

Há muito tempo é conhecida a estreita conexão entre publicidade e democracia. Para que a sociedade possa avaliar e controlar a conduta de seus governantes, a visibilidade do poder é imprescindível. Na década de 1980, contudo, Bobbio escrevia, em tom de amargura, que "entre as promessas não cumpridas da democracia (...) a mais grave e prejudicial e, ao que parece, também a mais irremediável, é precisamente a transparência do poder" ${ }^{, 427}$.

Tivessem as normas de acesso à informação se limitado a afirmar que a publicidade é a regra e o sigilo a exceção, talvez estivéssemos apenas diante de mais uma promessa vã, destinada ao não cumprimento. Mas o seu traço distintivo está justamente no seu compromisso com a efetividade daquele preceito. Nesse sentido, no nível internacional tem se construído uma política legislativa em torno do direito de acesso, voltada à proposição de mecanismos jurídicos e arranjos institucionais com o objetivo de, por um lado, aumentar a acessibilidade e usabilidade das informações detidas por entidades públicas e, por outro, reduzir o sigilo ao mínimo necessário à preservação de interesses legítimos.

No plano nacional, a Lei de Acesso à Informação incorporou muitos desses elementos, reforçando as obrigações de divulgação ativa de informações por parte dos órgãos e entidades públicas, criando canais e procedimentos para a solicitação de dados e documentos, delimitando hipóteses de sigilo e fixando mecanismos para seu controle, entre outras medidas. Em poucos anos de vigência, a LAI, reconhecida internacionalmente como uma lei "forte", tem oportunizado mudanças significativas na cultura administrativa brasileira.

Apesar de sua elevada aderência aos parâmetros internacionais, a lei brasileira apresenta também limitações, dentre as quais o tratamento dispensado às empresas estatais. Ao mesmo tempo em que subordina essas entidades aos mandamentos de transparência mais uma prova de seu compromisso com as diretrizes internacionais -, a lei peca ao silenciar sobre as especificidades dessas organizações e, em especial, sobre a proteção à confidencialidade de informações empresariais.

Como espero ter deixado claro ao longo da dissertação, na falta de uma disciplina legal específica sobre o sigilo econômico, a administração pública federal viu-se forçada a

${ }^{427}$ Democracia e segredo, p. 64. 
construir, não sem alguns contorcionismos argumentativos, uma interpretação capaz de proteger interesses das empresas estatais que poderiam ser prejudicados pela divulgação de certas informações.

Isso não significa que a prática da administração pública seja ilegal ou ilegítima. Com efeito, não parece haver grande controvérsia quanto à existência de um interesse público relevante na preservação da viabilidade econômica das empresas estatais. Tampouco se questiona que o ordenamento jurídico brasileiro protege, de forma difusa, a confidencialidade de informações empresariais, o que dá margem à interpretação sistemática que fundamenta as restrições de acesso no âmbito da administração pública federal.

Ainda assim, o atual tratamento dispensado ao sigilo econômico parece disfuncional, se analisado à luz dos propósitos da Lei de Acesso à Informação. Em primeiro lugar, porque a ausência de um regramento claro sobre o assunto - como discutido no Capítulo 4 - gera grande insegurança jurídica, tanto para os eventuais interessados em obter acesso às informações, quanto para as próprias empresas estatais, cuja gestão informacional fica à mercê dos entendimentos - algo imprevisíveis - das instâncias recursais nos casos concretos. Em segundo lugar, as modalidades de sigilo econômico não foram adequadamente contempladas no desenho institucional proposto pela LAI, sendo perceptível, em relação a elas, uma especial precariedade dos mecanismos que seriam responsáveis por circunscrever o sigilo ao mínimo necessário, como vimos no Capítulo 5.

Seriam necessários estudos empíricos mais aprofundados para verificar se hoje, de fato, o sigilo econômico tem dimensão mais ampla do que a que seria imprescindível para a proteção dos interesses legítimos das empresas estatais. Ainda assim, parece seguro afirmar que (i) uma eventual expansão do sigilo econômico seria de difícil controle pelo modelo atual e (ii) a mera ausência de regramento já configura um obstáculo ao controle social das empresas estatais, na medida em que não dificulta enormemente à sociedade civil tomar conhecimento de quais e quantas informações estão sendo mantidas longe do olhar do público. Ou seja, a própria dimensão do sigilo é, de certo modo, um segredo.

Não se pretende com isso afirmar que a LAI, no tocante ao sigilo econômico, represente um retrocesso. Na verdade, a lei deu espaço a uma discussão até então praticamente inexistente, e a atuação da CGU em relação às empresas estatais, ainda que limitada, parece ter contribuído para reduzir a opacidade dessas organizações. Esses 
aparentes avanços, porém, não elidem o descompasso existente entre o tratamento do sigilo econômico e as diretrizes internacionais sobre acesso à informação.

$\mathrm{O}$ aparente descuido em relação às empresas estatais, no entanto, não deve ser entendido como exclusividade do direito brasileiro. Na verdade, o estudo dos documentos internacionais sobre acesso à informação, ou mesmo da literatura acadêmica a respeito do tema, indica que pouca atenção tem sido dada ao regime peculiar em que essas entidades desenvolvem suas atividades. Algumas das premissas que servem de base ao direito de acesso à informação, tal como concebido correntemente, enfrentam obstáculos quando de sua transposição para o âmbito empresarial. Para ficar em único exemplo, muitas das regras associadas ao direito de acesso amparam-se na premissa de que a informação custodiada pelos órgãos e entidades públicos não é do Estado, e sim da própria sociedade, sendo o poder público mero detentor das informações com vistas ao desempenho das funções que lhe são atribuídas; seria esse mesmo raciocínio aplicável, porém, às sociedades de economia mista, tendo em vista a existência de acionista privado minoritário?

Nesse sentido, não seria irrazoável questionar até que ponto o desenho jurídicoinstitucional proposto pela política legislativa internacional - tendo como ponto focal a administração direta - é de fato adequado às empresas estatais. Diante desses questionamentos, muitos países têm preferido deixar as empresas estatais - quando não todas, ao menos algumas - fora do alcance das normas de acesso à informação, conforme se discutiu no Capítulo 3. Essa solução, conquanto seja conveniente, não enfrenta a tormentosa questão da transparência e do controle social das empresas estatais.

A relevância dessa questão não deve ser subestimada. Primeiramente, porque há indícios de que empresas estatais são um locus privilegiado de corrupção. Além dos numerosos exemplos oferecidos pela experiência brasileira sobre o assunto, um relatório da OCDE que analisou 427 investigações de corrupção de agentes públicos estrangeiros concluiu que em $27 \%$ dos casos os receptores de propina eram funcionários de empresas estatais, sendo que, em relação ao volume dos pagamentos, esses empregados receberam $80 \%$ do valor total distribuído em propina ${ }^{428}$.

Não é só o combate à corrupção que gera pressão em favor da transparência, até porque o Estado conta com diversos órgãos de controle com competência para apurar essas irregularidades e punir os responsáveis. Talvez ainda mais relevante seja a necessidade de

428 ORGANIZAÇÃO PARA A COOPERAÇÃO E DESENVOLVIMENTO ECONÔMICO. OECD Foreign Bribery Report: an analysis of the crime of bribery of foreign public officials. Paris: OECD Publishing, 2014, pp. 23-4. 
oferecer à sociedade instrumentos adequados para a avaliação democrática das ações de seus governantes. Seria ingenuidade pensar que as decisões das empresas estatais não refletem, em maior ou menor grau, orientações políticas dos governos a que estão vinculadas. Trata-se, portanto, de accountability. Estaria a Petrobras controlando o preço dos combustíveis a pedido do governo para conter a inflação ${ }^{429}$ ? É possível que a Companhia de Saneamento Básico do Estado de São Paulo - SABESP esteja omitindo dados sobre a crise hídrica ${ }^{430}$ ? A diretoria da Caixa Econômica Federal sabia ou não da possível ilegalidade das chamadas "pedaladas fiscais", que fundamentaram o impeachment da presidente Dilma Rousseff ${ }^{431}$ ?

Mesmo após privatizações realizadas por diversos países nas décadas de 1980 e 1990, é inegável que as empresas estatais ainda desempenham um papel relevante, tanto na economia global, como na implantação de políticas públicas. Assim, não se pode prescindir do controle social em relação a essas entidades; pelo contrário, é possível argumentar que aqui - na intervenção do Estado na economia - é justamente onde a transparência se faz mais necessária, pois, como já advertia Bobbio, “à diferença do poder legislativo e do poder executivo tradicional, o governo da economia pertence em grande parte à esfera do poder invisível, na medida em que se subtrai (se não formalmente, ao menos substancialmente) ao controle democrático e ao controle jurisdicional"432.

${ }^{429}$ Entre 2013 e 2014, a imprensa noticiou que a Petrobras estaria, a pedido do governo federal, mantendo os preços dos combustíveis em patamares artificialmente baixos, com o objetivo de controlar a inflação (Petrobras é sacrificada no controle de preços. O Globo. Rio de Janeiro, 3 dez. 2013). O governo, no entanto, negou a prática em reiteradas ocasiões (Dilma diz ser contra tarifaço e nega controle de preços pelo governo. Valor Econômico. São Paulo, 8 de set. 2014). Vale lembrar que a CGU já reconheceu o sigilo sobre as motivações das decisões de reajuste do preço de combustível nesse mesmo período (Parecer n. 2043 de 25/05/2016, NUP 99909.000348/2016-14).

430 Durante a crise hídrica que atingiu o Estado de São Paulo entre 2014 e 2015, a SABESP foi criticada por supostamente ocultar informações da população, minimizando com isso a gravidade da situação (cf., por exemplo, o editorial "Falta de água é coisa séria". Folha de S. Paulo. São Paulo, 9 set. 2014). A questão gerou diversos inquéritos no Ministério Público (Crise hídrica em São Paulo já gerou mais de 50 ações e inquéritos no MP. Portal G1. São Paulo, 18 ago. 2015). Cf. ainda ARTIGO 19. Sistema Cantareira e a Crise da Água em São Paulo: a falta de transparência no acesso à informação. São Paulo: Artigo 19, 2014.

${ }^{431}$ Em abril de 2016, o jornal O Globo afirmou que a diretoria da Caixa Econômica Federal teria feito pagamentos a programas sociais do governo mesmo tendo sido orientada em sentido contrário pelo Conselho de Administração da empresa. A realização de pagamentos pelos bancos estatais foi um dos pontos que levaram à reprovação das contas da Presidência da República pelo Tribunal de Contas da União relativas ao exercício financeiro de 2014. A revelação do jornal baseou-se nas atas do órgão colegiado, as quais, no entanto, são consideradas sigilosas (Caixa ignorou recomendação de Conselho contra 'pedaladas fiscais'. O Globo. Rio de Janeiro, 9 abr. 2016).

432 O Futuro da Democracia, p. 117. Para Bobbio, o governo da economia integra aquilo que o autor chama de subgoverno: "Talvez tenha chegado o momento de se tentar uma teoria do subgoverno, do qual existe apenas - e como! - uma prática. Tal prática está estreitamente conectada àquela função do estado póskeynesiano (...) que é o governo da economia. Onde o estado assumiu a tarefa do governar a economia, a classe política exerce o poder não mais apenas através das formas tradicionais da lei, do decreto legislativo, dos vários tipos de atos administrativos — que, desde quando existem um regime parlamentar 
Caso se pretenda fazer cumprir a promessa democrática da visibilidade do poder também em relação à atuação empresarial do Estado, portanto, é importante que mais atenção seja dada ao tema dos sigilos econômicos. Foge ao escopo deste trabalho apontar uma solução para o dilema enfrentado pelas empresas estatais; no entanto, o trabalho desenvolvido permite vislumbrar alguns pontos de atenção no enfrentamento da questão. $\mathrm{O}$ primeiro e mais evidente é a necessidade de um regramento claro a respeito das modalidades de sigilo econômico, o qual permita identificar em que circunstâncias o interesse empresarial das empresas estatais será protegido e os procedimentos envolvidos na delimitação das informações necessárias à preservação desse interesse, o que inclui a definição de competências internas para imposição da restrição de acesso.

Outro ponto de grande relevância é a temporalidade do segredo. O sigilo econômico das empresas estatais, enquanto expressão de sigilo-instrumento, deve ser assegurado apenas pelo tempo necessário à proteção do interesse subjacente, após o qual as informações devem preferencialmente ser disponibilizadas de forma ostensiva. Com isso, viabiliza-se a longo prazo o controle social, na medida em que se impede que informações relevantes passem direto da obscuridade para a eliminação, sem a possibilidade de seu estudo por parte da sociedade.

Por fim, seria de grande valia ao controle social conferir alguma visibilidade ao segredo, isto é, criar mecanismos que permitam à sociedade identificar, dentro do universo de informações custodiadas pelas empresas estatais, quais estão sendo tratadas como de acesso restrito, permitindo com isso um melhor dimensionamento do problema. $\mathrm{Na}$ impossibilidade de um sistema rigoroso de classificação, nos moldes das informações imprescindíveis à segurança do Estado e da sociedade, já traria ganhos significativos, por exemplo, a obrigatoriedade de divulgação, em transparência ativa, de todas os pedidos de acesso que tenham sido negados por motivos de sigilo, bem como da relação de dados e documentos que foram categorizados como confidenciais quando de seu fornecimento aos órgãos de controle interno e externo.

Ao discutir a aplicação da Lei de Acesso à Informação às empresas estatais brasileiras, em especial quanto às modalidades de sigilo econômico, a presente dissertação pretendeu lançar luzes sobre um tema ainda pouco estudado no direito brasileiro. Soma-se

e um estado de direito (um estado, entenda-se, em que os atos da administração pública são submetidos a um controle jurisdicional), começaram a fazer parte da esfera do poder visível —, mas também através da gestão dos grandes centros de poder econômico (bancos, indústrias estatais, indústrias subvencionadas, etc), da qual acima de tudo extrai os meios de subsistência dos aparatos dos partidos, dos aparatos dos quais por sua vez extrai, através das eleições, a própria legitimação para governar”. 
com isso a outras pesquisas que, aos poucos, vão revelando os percalços, os caminhos e as perspectivas do direito de acesso à informação no Brasil e no estrangeiro. O trabalho aqui desenvolvido, portanto, serve como contribuição para um esforço mais amplo de reflexão sobre os desafios envolvidos no cumprimento daquela velha promessa da democracia: a transparência do poder. 


\section{REFERÊNCIAS}

ACKERMAN, John M.; SANDOVAL-BALLESTEROS, Irma E. The Global Explosion of Freedom of Information Laws. Administrative Law Review, Vol. 58, n. 1, pp. 85-130, 2006.

ALEXANDER, Shannon; MCDERMOTT, Patrice. A Case Study of the United States. In: TRAPNELL, Stephanie E. Right to Information: case studies on implementation. Right to information working paper series. Washington: World Bank Group, 2014, pp. 539-624.

AMORIM, Cláudia Nóbrega de Andrade de. Regime Jurídico das Atividades Nucleares. Revista da Advocacia Geral da União, v. 9, n. 23, pp. 65-96, jan./mar., 2010.

ANGÉLICO, Fabiano. Lei de Acesso à Informação. São Paulo: Estudos Editores, 2015.

Lei de acesso à informação pública e seus possíveis desdobramentos para a accountability democrática no Brasil. Dissertação de Mestrado. Escola de Administração de Empresas de São Paulo. Fundação Getúlio Vargas, 2012.

APRIGLIANO, Ricardo de Carvalho. Insider Trading. Revista de Direito Mercantil, Industrial, Econômico e Financeiro, v. 36. n. 109. pp.173-82, jan./mar. 1998.

ARAGÃO, Alexandre Santos de. Empresas Estatais: o regime jurídico das empresas públicas e sociedades de economia mista. São Paulo: Forense, 2017.

ARCHIBALD, Sam. The Early Years of the Freedom of Information Act: 1955 to 1974 PS: Political Science and Politics, v. 26, n. 4, pp. 726-731, 1993, Disponível em: <www.jstor.org/stable/419539>, acesso em: 13/07/2017.

ARTICLE 19. Access to Information: an instrumental right for empowerment. Disponível em < https://goo.gl/LL3emy>. Acesso em: 15/06/2017.

ARTIGO 19. Sistema Cantareira e a Crise da Água em São Paulo: a falta de transparência no acesso à informação. São Paulo: Artigo 19, 2014. Disponível em: <https://goo.gl/D8Eo5T>, acesso em 25/07/2017.

Leis de Acesso à Informação: dilemas da implementação. 2011. Disponível em: < https://goo.gl/wTSvvy>, acesso em 15/06/2017.

BANDEIRA DE MELLO, Celso Antonio. Sociedades mistas, empresas públicas e o regime de direito público. In: DI PIETRO, Maria Silvia Z.; SUNDFELD, Carlos Ari (org.). Administração pública indireta e regulação. São Paulo: Editora Revista dos Tribunais, 2012, pp. 671-680.

BANISAR, David. Freedom of Information Around the World 2006: a global survey of access to government records laws. Privacy International, 2006. Disponível em: < https://goo.gl/zW9eVY>, acesso em 17/07/2017. 
BARONE, Daniela Marcos. A Proteção Internacional do Segredo Industrial. Dissertação de Mestrado. Faculdade de Direito da Universidade de São Paulo. 2009, 133p.

BARRETO, Aires Fernandino. Pessoa administrativa não aufere lucro nem tem prejuízo. Tem superavit ou deficit. Revista Trimestral de Direito Público. São Paulo, n. 6, pp. 259-62, 1994.

BENTO, Leonardo Valles. Acesso a Informações Públicas: princípios internacionais e o direito brasileiro. Curitiba: Juruá, 2015.

BEZERRA FILHO, Manoel Justino. Lei de recuperação de empresas e falência: Lei 11.101/2005. $11^{\text {a }}$ ed. São Paulo: Editora Revista dos Tribunais, 2016.

BLANTON, Thomas S. The Global Openness Movement in 2006: 240 Years after the First Freedom of Information Law, Access to Government Information Now Seen as a Human Right. In: MUSTONEN, J. (ed.). The World's First Freedom of Information Act, Kokkola: Anders Chydenius Foundation, 2006, pp. 80-97.

BLOK, Marcella. Insider trading: o descumprimento do dever de lealdade pelo uso de informações privilegiadas. Revista de Direito Bancário e do Mercado de Capitais, v. 15, n. 55, pp. 83-129, jan./mar. 2012.

BOBBIO, Norberto. Democracia e Segredo. Tradução de Marco Aurélio Nogueira. São Paulo: Editora Unesp, 2015.

. O Futuro da Democracia: uma defesa das regras do jogo. Tradução de Marco Aurélio Nogueira. 10ª ed. São Paulo: Paz e Terra, 2006, pp. 97-120.

BRAGA, Rodrigo Bernardes. O Segredo de Negócio no Direito Brasileiro. Revista da ABPI, n. 101, pp. 29-42, jul./ago. 2009.

BUENO NETTO, Patrícia. Lei de acesso às informações públicas e sigilos: breve comparação entre as normas brasileira e norte-americana. Revista Trimestral de Direito Público. São Paulo, n. 63, pp. 97-110, 2015.

CALLAND, Richard. Prizing Open the Profit-Making World. In: FLORINI, Ann. The Right to Know: transparency for an open world. Nova York: Columbia University Press, 2007, pp. 214-242.

CARDOSO, André Guskow. Governança Corporativa, Transparência e Compliance nas Empresas Estatais: o regime instituído pela Lei 13.303/2016. In: JUSTEN FILHO, Marçal (org.). Estatuto Jurídico das Empresas Estatais: Lei 13.303/2016. São Paulo: Editora Revista dos Tribunais, 2016, pp. 95-120.

CARVALHO, Igor Chagas de. A tensão ente o direito à informação e o direito à privacidade e o acesso aos arquivos sensíveis. Revista de informação legislativa, v. 51, n. 202, pp. 115-130, abr./jun. 2014.

CARVALHO, Juliane Erthal de; COSTA, Camila Batista Rodrigues. Fiscalização das Empresas Estatais pelo Tribunal de Contas. In: JUSTEN FILHO, Marçal (org.). Estatuto 
Jurídico das Empresas Estatais: Lei 13.303/2016. São Paulo: Editora Revista dos Tribunais, 2016, pp. 607-626.

CARVALHOSA, Modesto. Comentários à lei de sociedades anônimas: Lei $\mathrm{n}^{\circ} 6.505$, de 15 de dezembro de 1976. $2^{\text {a }}$ ed. São Paulo: Saraiva, 1998.

CLÈVE, Clèmerson Merlin; FRANZONI, Julia Ávila. Administração pública e a nova Lei de Acesso à Informação. Interesse Público. Belo Horizonte, v. 15, n. 79, pp. 15-40. maio/jun. 2013.

COELHO, Fábio Ulhoa. Curso de direito comercial, vol. $1.17^{\mathrm{a}}$ ed. São Paulo: Saraiva, 2013.

COLIVER, Sandra. The Right to Information and the Expanding Scope of Bodies Covered by National Laws since 1989. In: MOLNÀR, Péter. (ed.) Free Speech and Censorship Around the Globe. Budapest: Central European University Press, 2015, pp. 187-210.

COLLOR, Fernando. Lei de acesso à informação pública, questão de estado: o debate sem distorções. Brasília: Senado Federal, Senador Fernando Collor, 2011. Disponível em: <http://www2.senado.leg.br/bdsf/handle/id/243028>, acesso em 25/06/2017.

COMPARATO, Fábio Konder. A regra do sigilo nas ofertas públicas de aquisição de ações. In: . Direito Empresarial: Estudos e Pareceres. São Paulo, Saraiva, 1990.

CONTROLADORIA GERAL DA UNIÃO. Aplicação da Lei de Acesso à Informação na Administração Pública Federal, $2^{\mathrm{a}}$ ed., 2016. Disponível em: < https://goo.gl/KQikgn >, acesso em 15/07/2017.

CUNHA FILHO, Márcio Camargo; XAVIER, Vitor César Silva. Lei de Acesso à Informação: teoria e prática. Rio de Janeiro: Lumen Iuris, 2014

DINIZ, Davi Monteiro. Propriedade Industrial e Segredo em Comércio. Belo Horizonte: Del Rey, 2003.

EIZIRIK, Nelson. A Lei das S/A Comentada. São Paulo: Quartier Latin, 2011.

FEISER, Craig D. Privatization and the Freedom of Information Act: An Analysis of Public Access to Private Entities Under Federal Law. Federal Communications Law Journal, v. 52, pp. 21-62, 2000.

FEKETE, Elisabeth Edith G. Kasnar. Perfil do segredo de indústria e comércio no direito brasileiro: identificação e análise crítica. Tese de Doutorado. Faculdade de Direito da Universidade de São Paulo. 1999. 485p.

FERNANDEZ; Javier; MORAIS, Gustavo de Freitas. Segredo Industrial versus lei de acesso à informação: uma contradição? Rio de Janeiro: Lumen Juris, 2014.

FERREIRA, Alexsandro Fonseca; MAZZEI, Marcelo Rodrigues; GERAIGE NETO, Zaiden. $\mathrm{O}$ direito coletivo de acesso à informação pública: um estudo comparado entre a 
legislação brasileira e a colombiana. A\&C: Revista de Direito Administrativo e Constitucional. Belo Horizonte, v. 13, n. 53, pp. 177-94, jul./set. 2013.

FLORINI, Ann (Org.). The Right to Know: Transparency for an Open World. Nova York: Columbia University Press, 2007.

FOX, Jonathan; HAIGHT, Libby. Mexico's transparency reforms: theory and practice. Research in Social Problems and Public Policy, v. 19, 2011. pp. 353-379. Disponível em: <http://goo.gl/jh946P>. Acesso em 11/05/2017.

FORTINI, Cristiana; AVELAR, Mariana Magalhães; FERREIRA, Raquel Bastos. Comentários à Lei de Acesso à Informação: contexto, desafios e polêmicas. In: MARQUES NETO, Floriano de Azevedo; MENEZES, Fernando Dias; NOHARA, Irene Patrícia; MARRARA, Thiago (org.). Direito e Administração Pública: estudos em homenagem a Maria Sylvia Zanella Di Pietro. São Paulo: Editora Atlas, 2013, pp. 1015-48.

FROTA, Maria Guiomar da Cunha. Comissão Nacional da Verdade e Lei de Acesso à Informação: informação, memória e justiça no contexto democrático pós-1988. In: MOURA, Maria Aparecida (org.). A construção social do acesso público à informação no Brasil: contexto, historicidade e repercussões. Belo Horizonte: editora UFMG, 2014, pp. 71-84.

HEINEN, Juliano. Comentários à Lei de Acesso à Informação. Belo Horizonte: Fórum, 2014.

Lei de acesso à informação (Lei n ${ }^{\circ}$ 12.527/2011) - Para uma interpretação constitucional do pedido de acesso. Revista Brasileira de Direito Público, v. 11, n. 41, pp. 53-68, abr./jun. 2013

HERANES NETO, Halley. Lei de acesso à informação - aspectos relativos ao sigilo fiscal e ao procedimento administrativo tributário. Revista do Advogado, v. 32, n. 118, pp. 5360, dez. 2012.

JUSTEN FILHO, Marçal (org.). Estatuto Jurídico das Empresas Estatais: Lei 13.303/2016. São Paulo: Editora Revista dos Tribunais, 2016.

Comentários à Lei de Licitações e Contratos Administrativos. 17 $7^{\mathrm{a}}$ ed., São Paulo: Editora Revista dos Tribunais, 2016.

Curso de Direito Administrativo, $10^{\mathrm{a}}$ ed. São Paulo: Editora Revista dos Tribunais, 2014.

. Empresas estatais e a superação da dicotomia "prestação de serviço público / exploração de atividade econômica". In: FIGUEIREDO, Marcelo; PONTES FILHO, Valmir (Org.). Estudos de Direito Público em homenagem a Celso Antonio Bandeira de Mello. São Paulo: Malheiros, 2006, pp. 403-423.

LABRUNIE, Jacques. A Proteção ao Segredo de Negócio. In: SIMÃO FILHO, Adalbert; LUCCA, Newton de. Direito Empresarial Contemporâneo. São Paulo: Juarez de Oliveira, 2000, pp. 85-105. 
LAEBER, Márcio Rafael Silva. Proteção de dados pessoais: o direito à autodeterminação informativa. Revista de Direito Bancário e do Mercado de Capitais, v. 10. n. 37, pp. 5980, jul./set. 2007.

LATTOUF, Regis. Lei de Acesso à Informação - Lei $\mathrm{n}^{\circ}$ 12.527/11: proposta de classificação das informações segundo as categorias de acesso. In: AUAD, Denise; OLIVEIRA, Bruno Batista da Costa. Direitos Humanos, Democracia e Justiça Social: uma homenagem à Professora Eunice Prudente - da militância à academia. São Paulo: Letras Jurídicas, 2017, pp. 523-540.

LEÃES, Luiz Gastão Paes de Barros. A adoção do Chinese Wall e a repressão ao insider trading. Revista de Direito Bancário e do Mercado de Capitais, v. 13. n. 47, pp. 227-45, jan./mar. 2010.

MACIEL, Karina Teresa da Silva; MARTIN, Antônio. Efetividade da repressão ao insider trading. Revista de Direito Empresarial, v. 2. n. 3, pp.149-76, mai./jun. 2014.

MANCUSO, Wagner Pralon; ANGÉLICO, Fabiano; GOZETTO, Andréa Cristina Oliveira. Ferramentas da transparência: o possível impacto da Lei de Acesso a Informações Públicas no debate sobre regulamentação do lobby no Brasil. Revista de Informação Legislativa, v. 53, n. 212, pp. 41-56, out./dez. 2016.

MARINO, Catalina Botero. O Direito de Acesso à Informação no Marco Jurídico Interamericano. Relatoria Especial para a Liberdade de Expressão (OEA/Ser.L/V/II. CIDH/RELE/INF. 9/12), Comissão Interamericana de Direitos Humanos, 2012.

MARQUES NETO, Floriano de Azevedo; DE PALMA, Juliana Bonacorsi. Empresas estatais e parcerias institucionais. Revista de Direito Administrativo, Rio de Janeiro, v. 272, p. 59-92, nov. 2016.

; CUNHA, Carlos Eduardo Bergamini. Serviços Sociais Autônomos. Revista de Direito Administrativo, n. 263, 2013, pp. 135-174

MARRARA, Thiago. O princípio da publicidade: uma proposta de renovação. In:

(Org.). Princípios de Direito Administrativo. São Paulo: Atlas, 2012, pp. 280-300.

MARTINS, Fran. Comentários à Lei das Sociedades Anônimas. 4.ed. rev. e atual. por PAPINI, Roberto. Rio de Janeiro: Forense, 2010.

MARTINS, Ricardo. Restrições ao acesso à informação. In: VALIM, Rafael; MALHEIROS, Antonio Carlos; BACARIÇA, Josephine (in memoriam) (coord.). Acesso à Informação Pública. Belo Horizonte: Fórum, 2015, pp. 111-134.

MARTINS JUNIOR, Wallace Paiva. Princípio da Transparência. In: DI PIETRO, Maria Sylvia Zanella (coord.). Tratado de direito administrativo, v.1. São Paulo: Thomson Reuters Revista dos Tribunais, 2015, pp. 419-82.

A Lei de Acesso a Informações Públicas (Lei $n^{\circ}$ 12.527/11). In: MARQUES NETO, Floriano de Azevedo; MENEZES, Fernando Dias; NOHARA, Irene Patrícia; 
MARRARA, Thiago (org.). Direito e Administração Pública: estudos em homenagem a Maria Sylvia Zanella Di Pietro. São Paulo: Editora Atlas, 2013, pp. 989-1014.

. Princípio da publicidade. In: MARRARA, Thiago (org.). Princípios de Direito Administrativo. São Paulo: Atlas, 2012, pp. 233-258.

MÁXIMO, Marcela de Fátima Menezes; AOKI, Raquel Lima de Abreu; AOKI, William Ken. Do direito de acesso à informação pública em poder do Estado - a visão do Sistema Interamericano de Direitos Humanos. Revista Brasileira de Direito Público. Belo Horizonte, v. 10, n. 38, pp. 115-44, jul./set. 2012

MELLO, Shirlei Silmara de Freitas. Motivação, publicidade e controle: algumas reflexões. In: MARRARA, Thiago (org.). Princípios de Direito Administrativo. São Paulo: Atlas, 2012, pp. 301-24.

MENCARINI, Fabrizio. Transparência nos bancos públicos brasileiros: um estudo sobre a implementação da Lei de Acesso à Informação (LAI) no Banco do Brasil (BB), Caixa Econômica Federal (CEF) e Banco Nacional de Desenvolvimento Econômico e Social (BNDES). Dissertação de Mestrado. Escola de Administração de Empresas de São Paulo. Fundação Getúlio Vargas, 2015.

MENDEL, Toby. Designing Right to Information Laws for Effective Implementation. Right to information working paper series. Washington: World Bank Group, 2015.

Right to Information: Recent Spread in RTI Legislation. Right to information working paper series. Washington: World Bank Group, 2014.

2008.

Freedom of Information: a comparative legal survey. 2. ed. Paris: UNESCO,

MENDES, Rodrigo. Impacto da Lei de Acesso à Informação: os casos da Agência Nacional de Petróleo, Gás Natural e Biocombustíveis e das agências reguladoras federais. Dissertação de Mestrado. Escola Brasileira de Administração Pública e de Empresas, Fundação Getúlio Vargas. Rio de Janeiro, 2014.

MICHENER, Gregory. Assessing Freedom of Information in Latin America a Decade Later: Illuminating a Transparency Causal Mechanism. Latin American Politics and Society, n.57, pp. 77-99, 2015. abr. 2011.

FOI Laws Around the World. Journal of Democracy, v. 22, n. 2, pp. 145-159,

The Surrender of Secrecy: Explaining the Emergence of Strong Access to Information Laws in Latin America. Tese de Doutorado. University of Texas, 2010, 498p.

MIGLIARI JÚNIOR, Arthur. Artigo 169. In: TOLEDO, Paulo F.C. Talles de; ABRÃO, Carlos Henrique (coord.). Comentários à Lei de Recuperação de Empresas e Falência. $5^{\text {a }}$ ed. rev., atual. e ampl. São Paulo, Saraiva: 2012. 
MONTEIRO, Carina Villela de Andrade. Direito à privacidade versus direito à informação: considerações sobre a possibilidade de órgãos públicos fornecerem a terceiros informações pessoais de agentes públicos. Revista de Informação Legislativa, v. 44, n. 173, pp. 27-40, jan./mar. 2007.

MOREIRA NETO, Diogo de Figueiredo; SOUTO, Marcos Juruena Villela. Arbitragem em contratos firmados por empresas estatais. Revista de Direito Administrativo, Rio de Janeiro, v. 236, pp. 215-262, abr. 2004.

Natureza Jurídica dos Serviços Sociais Autônomos. Revista de Direito Administrativo, n. 207, pp. 79-94, 1997.

MOTA, Fernando de Andrade. O Dever de Divulgar Fato Relevante na Companhia Aberta. São Paulo: Almedina, 2015.

MOTTA, Fabrício. O princípio constitucional da publicidade administrativa. In: MARRARA, Thiago (org.). Princípios de Direito Administrativo. São Paulo: Atlas, 2012, pp. 259-79.

MOTTA, Nelson Candido. Do acesso aos livros societários: notas para uma interpretação sistemática e teleológica do $\S 1^{\circ}$ do art. 100 da lei de S/A. Revista de Direito Mercantil, Industrial, Econômico e Financeiro, v. 37. n. 115. pp. 127-9, jul./set. 1999.

MUSTONEN, Juha. (ed.). The World's First Freedom of Information Act. Kokkola: Anders Chydenius Foundation, 2006

NÓBREGA, Camila. Os 5 anos da Lei de Acesso à Informação: uma análise de casos de transparência. São Paulo: Artigo 19 Brasil, 2017.

NUNES, Márcio Tadeu Guimarães. Lei de Acesso à Informação: reconstrução da verdade histórica, ambientes regulatórios e o direito à intimidade. São Paulo: Quartier Latin, 2013.

ORGANIZAÇÃO PARA A COOPERAÇÃO E DESENVOLVIMENTO ECONÔMICO. OECD Foreign Bribery Report: an analysis of the crime of bribery of foreign public officials. Paris: OECD Publishing, 2014

ORIGA NETO, Pedro. Interpretação do art. $5^{\circ}$, XXXIII, da atual Constituição Federal e Lei 4.717 de 29.6.65. Revista de Direito Público, v. 22, n. 92, pp. 145-6, out./dez. 1989.

PAES, Eneida Bastos. Os desafios da implementação da nova Lei de Acesso à Informação - Lei 12.527/11. BDA: Boletim de Direito Administrativo. São Paulo, v. 29, n. 1, pp.2736, jan. 2013.

A influência internacional na construção do direito de acesso à informação no Brasil. Revista de Informação Legislativa. Brasília, v. 49, n. 195, pp. 245-57, jul./set. 2012.

PANOEIRO, Claudio de Castro. Corrupción,transparencia gubernamental y derecho de acceso a la información: un análisis comparativo de la ley de transparencia y acceso a 
la información brasileña. Dissertação de Mestrado. Universidade de Salamanca, 2014, $165 \mathrm{p}$.

PARENTE, Flávia. Concorrência desleal e segredos de fábrica e de negócio: análise do art. 195, XI, da lei da propriedade industrial (lei 9.279/1996). Revista de Direito Mercantil, Industrial, Econômico e Financeiro, v.54, n.139, pp.177-88, jul./set. 2005.

PERLINGEIRO, Ricardo. Princípios sobre o direito de acesso à informação oficial na América Latina. Revista de Investigações Constitucionais, v. 3, n. 2, pp. 143-197, mai./ago. 2016.

PINTO JUNIOR, Mario Engler. Empresa Estatal: função econômica e dilemas societários. $2^{\mathrm{a}}$ ed. São Paulo: Atlas, 2013.

PITOMBO, Antonio Sérgio A. de Moraes. Artigo 169. In: ; SOUZA JUNIOR, Francisco Satiro de. Comentários à Lei de Recuperação de Empresas e Falências. $2^{\mathrm{a}}$ ed. São Paulo: Editora Revista dos Tribunais, 2007.

PITTA, André Grünspun. O Regime de Informações das Companhias Abertas. São Paulo: Quartier Latin, 2013.

POLÍZIO JÚNIOR, Vladimir. Lei de Acesso à Informação: Manual Teórico e Prático. Curitiba: Juruá, 2015.

PROENÇA, José Marcelo Martins. Insider Trading: o primeiro caso de criminalização pela justiça brasileira. In: NOVAES FRANÇA, Erasmo Valladão Azevedo; VON ADAMEK, Marcelo Vieira. Temas de Direito Empresarial e Outros Estudos: em Homenagem ao Professor Luiz Gastão Paes de Barros Leães. São Paulo: Malheiros, 2014, pp. 253-293.

Insider Trading: regime jurídico do uso de informações privilegiadas no mercado de capitais. São Paulo, Quartier Latin, 2005.

PUDDEPHATT, Andrew. Exploring the Role of Civil Society in the Formulation and Adoption of Access to Information Laws: The Cases of Bulgaria, India, Mexico, South Africa, and the United Kingdom. Right to information working paper series. Washington: World Bank Group, 2009.

RIBEIRO, Marcia Carla Pereira; ALVES, Rosângela do Socorro. Por um estatuto jurídico para as sociedades estatais que atuam no mercado. Interesse Público. Belo Horizonte. v. 16, n. 83, pp.39-59, jan./fev. 2014.

RIEKKINEN, Mariya; SUKSI, Markku. Access to information and documents as a human right. Åbo: Åbo Akademi University, Institute for Human Rights, 2015.

ROBERTS, Alasdair S. A Great and Revolutionary Law? The First Four Years of India's Right to Information Act. Public Administration Review, v. 70, n. 6, nov./dez. 2010. Disponível em: <http://papers.ssrn.com/sol3/papers.cfm?abstract_id=1527858>. Acesso em: 10/05/2017. 
Structural Pluralism and the Right to Information. The University of Toronto Law Journal, v. 51, n. 3, pp. 243-271, 2001.

. Less Government, More Secrecy: Reinvention and the Weakening of Freedom of Information Law. Public Administration Review, v. 60, n. 4, pp. 308-320, jul./ago. 2000.

SALES, Ramiro Gonçalves. O Direito de Acesso à Informação Pública Administrativa. Rio de Janeiro: Lumen Juris, 2014.

SALGADO, Eneida Desiree. Lei de Acesso à Informação (LAI): comentários à Lei $\mathrm{n}^{\mathbf{o}}$ 12.527/2011 e ao Decreto no 7.724/2012. São Paulo: Atlas, 2015.

SALOMÃO NETO, Eduardo. Trust e Deveres de Lealdade e Sigilo na Sociedade Anônima Brasileira. In: CASTRO; Rodrigo Roche Monteiro de; WARDE JUNIOR, Walfrido Jorge; GUERREIRO, Carolina Dias Tavares. Direito Empresarial e Outros Estudos em Homenagem ao Professor José Alexandre Tavares Guerreiro. São Paulo: Quartier Latin, 2013, pp. 294-335.

SANTI, Eurico Marcos Diniz de (org.). Transparência fiscal e desenvolvimento: homenagem ao professor Isaias Coelho. São Paulo: FISCOSoft Editora, 2013.

SARLET, Ingo Wolfgang; MARTOS,, José Antonio Montilla; RUARO, Regina Linden (coord.). Acesso à Informação como Direito Fundamental e Dever Estatal. Porto Alegre: Livraria do Advogado Editora, 2016.

SCALZILLI, João Pedro; SPINELLI, Luis Felipe. A racionalidade econômica do combate ao insider trading: assimetria de informação e dano ao mercado. Revista de Direito Mercantil, Industrial, Econômico e Financeiro, v. 46, n. 147, pp. 42-54.

SCHIRATO, Vitor Rhein. As empresas estatais no Direito Administrativo Econômico atual. São Paulo: Saraiva, 2016.

Livre Iniciativa nos Serviços Públicos. Belo Horizonte: Fórum, 2012.

SCHUDSON, Michael. The Rise of the Right to Know: Politics and the Culture of Transparency, 1945-1975. Cambridge: Harvard University Press, 2015.

SCHWIND, Rafael Wallbach. Participação estatal em empresas privadas: as "empresas público-privadas". Tese de Doutorado. Faculdade de Direito, Universidade de São Paulo, São Paulo, 2014.

SILVEIRA, João Marcos. A Proteção Jurídica dos Segredos Industriais e de Negócio. Revista de Direito Mercantil, Industrial, Econômico e Financeiro, v. 40, n. 121, pp. 150-159.

SILVEIRA, Marco Antonio Karam. Lei de Acesso à Informação Pública (Lei 12.527/2011) - democracia, República e transparência no Estado constitucional. Revista dos Tribunais. São Paulo, v. 102, n. 927, pp.131-55. jan. 2013. 
SILVEIRA, Renato de Mello Jorge. As Disposições Penais na Lei de Recuperação de Empresas e de Falência: crimes em espécie e procedimento. In: MACHADO, Rubens Approbato. Comentários à Nova Lei de Falência e Recuperação de Empresa. $2^{a}$ ed. São Paulo: Quartier Latin, 2007, pp. 307-328.

SINGH, Shekhar. India: Grassroots Initiatives. In: FLORINI, Ann. The Right to Know: transparency for an open world. Nova York: Columbia University Press, 2007, pp. 19-53.

SZTAJN, Rachel. Direito Societário e Informação. In: CASTRO; Rodrigo Roche Monteiro de; WARDE JUNIOR, Walfrido Jorge; GUERREIRO, Carolina Dias Tavares. Direito Empresarial e Outros Estudos em Homenagem ao Professor José Alexandre Tavares Guerreiro. São Paulo: Quartier Latin, 2013, pp. 216-36.

SUNDFELD, Carlos Ari. Princípio da Publicidade Administrativa: direito de certidão, vista e intimação. In: DI PIETRO, Maria Silvia Z.; SUNDFELD, Carlos Ari (org.). Fundamentos e Princípios do Direito Administrativo . São Paulo: Editora Revista dos Tribunais, 2012, pp. 671-680.

SUSMAN, Thomas; JAYARATNAM, Ashwini, SNOWDEN, David; VASQUEZ, Michael. Enforcing the Public's Right to Government Information: Can Sanctions Against Officials for Nondisclosure Work? Rochester, NY: Social Science Research Network, 2012.

TEUBNER, Gunther. Verfassungsfragmente: Gesellschaftlicher Konstitutionalismus in der Globalisierung. Berlim: Suhrkamp, 2012.

TRAPNELL, Stephanie E.; LEMIEUX, Victoria. Right to Information: Identifying Drivers of Effectiveness in Implementation. Right to information working paper series. Washington: World Bank Group, 2014.

UNGARO, Gustavo Gonçalves; SORÉ, Raphael Rodrigues. Efetividade do Acesso à Informação como Direito Fundamental - Casuística administrativa do Estado de São Paulo. In: AUAD, Denise; OLIVEIRA, Bruno Batista da Costa. Direitos Humanos, Democracia e Justiça Social: uma homenagem à Professora Eunice Prudente - da militância à academia. São Paulo: Letras Jurídicas, 2017, pp. 493-522.

; CARVALHO, Guilherme Siqueira de. Participação, controle e transparência por meio das ouvidorias públicas. In: BASSOTI, Ivani Maria; SANTOS, Thiago Souza. Tópicos essenciais sobre gestão pública. São Paulo: Unidade Central de Recursos Humanos da Secretaria de Planejamento e Gestão, 2016, pp. 289-312.

VALLE, Vanice Regina Lírio do. Lei $\mathrm{n}^{\circ}$ 12.527/2011 e o planejamento da ação estatal: uma interpretação orientada a prevenir a desinformação. Revista de Direito Administrativo, Rio de Janeiro, v. 267, pp. 109-133, set. 2014.

VANELLI, Victor Hugo Pavoni. Fiscalização das empresas estatais pela sociedade. In: JUSTEN FILHO, Marçal (org.). Estatuto Jurídico das Empresas Estatais: Lei 13.303/2016. São Paulo: Editora Revista dos Tribunais, 2016, pp. 627-640. 


\section{APÊNDICE - RECURSOS DE ACESSO À INFORMAÇÃO SELECIONADOS PARA ANÁLISE DO SIGILO ECONÔMICO}

No âmbito desta pesquisa, foram analisadas 963 decisões proferidas pela Controladoria Geral da União entre maio de 2012 e fevereiro de 2017, relativas a 1382 recursos de acesso à informação interpostos contra 49 empresas estatais federais. Desse conjunto, foram selecionados 380 protocolos (relacionados abaixo), envolvendo 27 empresas, por versarem sobre a incidência ou não de sigilo econômico sobre as informações solicitadas.

\begin{tabular}{|c|c|c|}
\hline Empresa & NUP & Data da Decisão \\
\hline $\begin{array}{l}\text { ABGF - Agencia Brasileira Gestora de } \\
\text { Fundos Garantidores e Garantias S.A. }\end{array}$ & $00227.000017 / 2015-05$ & $11 / 11 / 2015$ \\
\hline \multirow[t]{2}{*}{ BASA - Banco da Amazônia S.A. } & $99904.000018 / 2015-80$ & $29 / 07 / 2015$ \\
\hline & $99904.000048 / 2016-77$ & 28/06/2016 \\
\hline \multirow{29}{*}{ BB - Banco do Brasil S.A. } & $99901.000617 / 2012-81$ & $28 / 11 / 2012$ \\
\hline & $99901.000692 / 2012-41$ & $25 / 02 / 2013$ \\
\hline & $99901.000977 / 2012-82$ & $15 / 04 / 2013$ \\
\hline & $99901.000459 / 2013-40$ & $21 / 05 / 2013$ \\
\hline & $99901.000496 / 2013-58$ & $27 / 05 / 2013$ \\
\hline & $99901.000100 / 2013-72$ & $10 / 06 / 2013$ \\
\hline & $99901.000180 / 2013-66$ & $10 / 06 / 2013$ \\
\hline & $99901.000181 / 2013-19$ & $10 / 06 / 2013$ \\
\hline & $99901.000881 / 2012-14$ & $12 / 06 / 2013$ \\
\hline & $99901.000884 / 2012-58$ & $12 / 06 / 2013$ \\
\hline & $99901.000882 / 2012-69$ & $12 / 06 / 2013$ \\
\hline & 99901.000632/2013-18 & 26/06/2013 \\
\hline & $99901.000183 / 2013-08$ & $03 / 07 / 2013$ \\
\hline & $99901.000219 / 2013-45$ & 03/07/2013 \\
\hline & 99901.000056/2013-09 & $12 / 07 / 2013$ \\
\hline & 99901.000101/2013-17 & $12 / 07 / 2013$ \\
\hline & 99901.000305/2013-58 & $02 / 08 / 2013$ \\
\hline & $99901.001028 / 2013-09$ & $15 / 10 / 2013$ \\
\hline & 99901.001356/2013-05 & $18 / 12 / 2013$ \\
\hline & 99901.001476/2013-02 & $20 / 12 / 2013$ \\
\hline & $99901.001475 / 2013-50$ & $20 / 12 / 2013$ \\
\hline & 99901.001555/2013-13 & $20 / 12 / 2013$ \\
\hline & 99901.001260/2013-39 & $13 / 01 / 2014$ \\
\hline & $99901.001259 / 2013-12$ & $13 / 01 / 2014$ \\
\hline & $99901.000916 / 2013-04$ & $16 / 01 / 2014$ \\
\hline & 99901.000714/2013-54 & $27 / 01 / 2014$ \\
\hline & 99901.001415/2013-37 & $10 / 02 / 2014$ \\
\hline & 99901.000020/2014-06 & $20 / 06 / 2014$ \\
\hline & $99901.001910 / 2013-46$ & 04/07/2014 \\
\hline
\end{tabular}




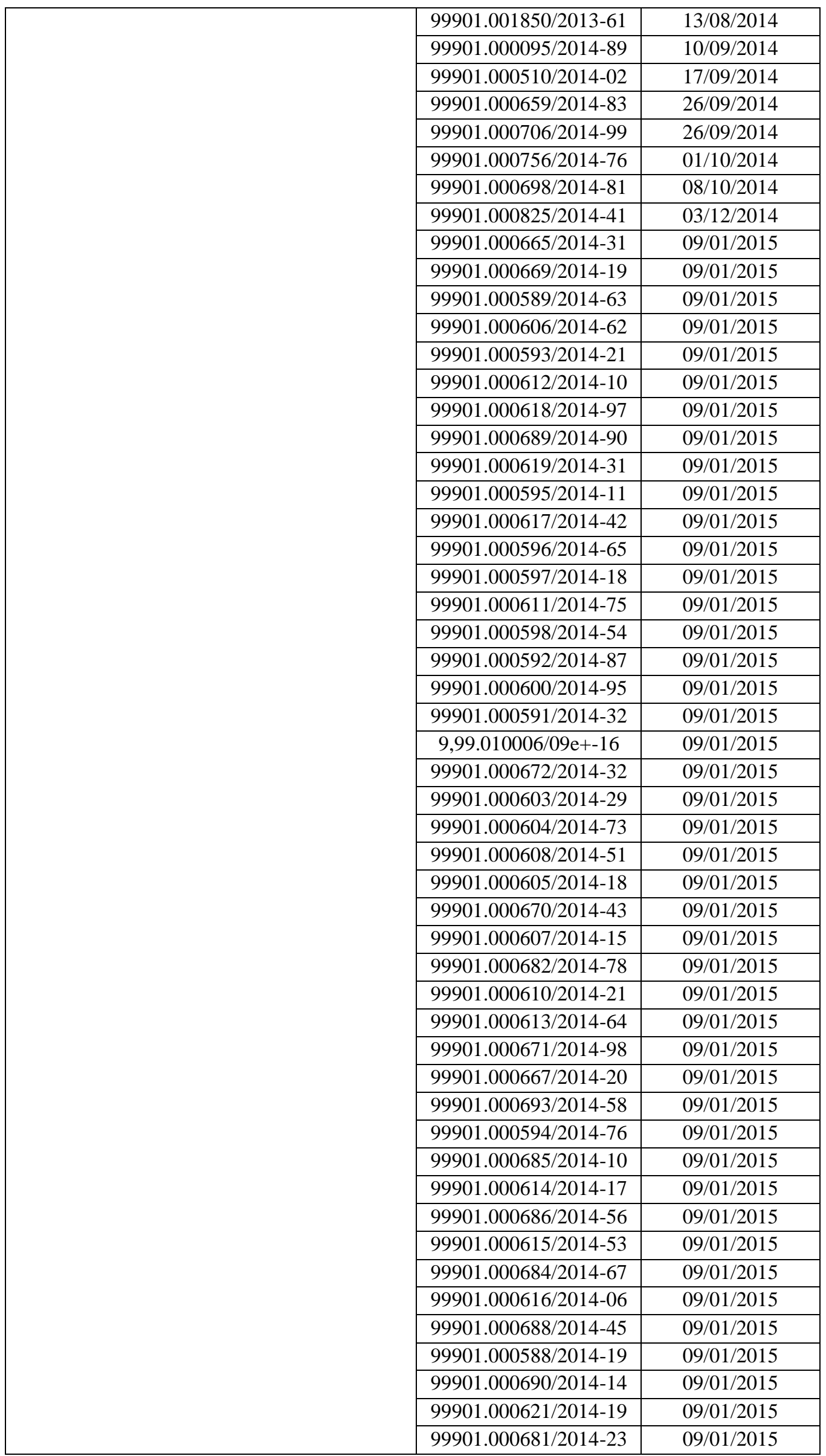




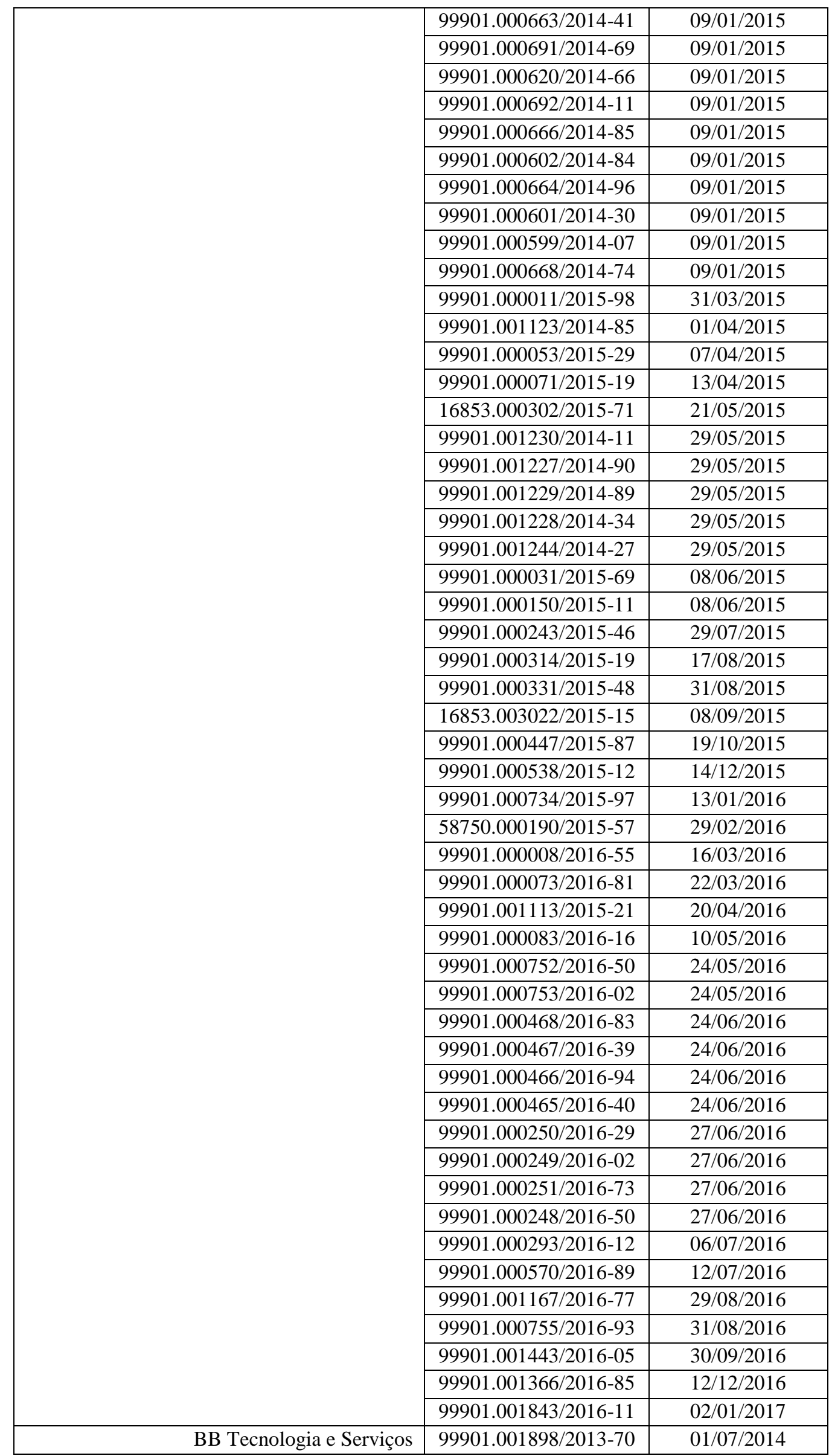




\begin{tabular}{|c|c|c|}
\hline & $99901.000282 / 2015-43$ & $29 / 07 / 2015$ \\
\hline & $99901.000222 / 2015-21$ & $14 / 12 / 2015$ \\
\hline & $99901.001192 / 2015-70$ & $17 / 02 / 2016$ \\
\hline & $99901.000612 / 2016-81$ & $22 / 07 / 2016$ \\
\hline & $99901.000511 / 2016-19$ & $22 / 07 / 2016$ \\
\hline & $10002.000095 / 2016-71$ & $30 / 01 / 2017$ \\
\hline \multirow[t]{7}{*}{ BNB - Banco do Nordeste do Brasil S.A. } & $99905.000095 / 2015-20$ & $24 / 08 / 2015$ \\
\hline & $99905.000094 / 2015-85$ & $25 / 08 / 2015$ \\
\hline & $99905.000022 / 2016-19$ & $04 / 05 / 2016$ \\
\hline & $99905.000021 / 2016-74$ & $04 / 05 / 2016$ \\
\hline & $99905.000047 / 2016-12$ & $06 / 05 / 2016$ \\
\hline & $99905.000135 / 2016-14$ & $15 / 08 / 2016$ \\
\hline & $99905.000245 / 2016-86$ & $16 / 12 / 2016$ \\
\hline \multirow{5}{*}{$\begin{array}{l}\text { BNDES - Banco Nacional de } \\
\text { Desenvolvimento Econômico e Social }\end{array}$} & $99903.000274 / 2013-15$ & $18 / 11 / 2013$ \\
\hline & $99903.000232 / 2013-84$ & $18 / 11 / 2013$ \\
\hline & $99903.000459 / 2013-20$ & $21 / 01 / 2014$ \\
\hline & $99903.000246 / 2015-60$ & $10 / 09 / 2015$ \\
\hline & $99903.000493 / 2015-66$ & $23 / 12 / 2015$ \\
\hline CEAL - Companhia Energética de Alagoas & $99908.000637 / 2015-34$ & $05 / 02 / 2016$ \\
\hline \multirow[t]{32}{*}{ CEF - Caixa Econômica Federal } & $99902.001665 / 2012-86$ & $23 / 01 / 2013$ \\
\hline & $99902.000062 / 2013-48$ & $11 / 03 / 2013$ \\
\hline & $99902.000068 / 2013-15$ & $28 / 03 / 2013$ \\
\hline & 99902.000049/2013-99 & $10 / 06 / 2013$ \\
\hline & 99902.000909/2013-94 & $10 / 09 / 2013$ \\
\hline & 99902.001030/2013-60 & $01 / 10 / 2013$ \\
\hline & 99902.001732/2013-43 & $24 / 03 / 2014$ \\
\hline & $99902.001733 / 2013-98$ & $28 / 04 / 2014$ \\
\hline & 99902.001753/2013-69 & $30 / 04 / 2014$ \\
\hline & $99902.001887 / 2013-80$ & $06 / 06 / 2014$ \\
\hline & $99902.002071 / 2013-73$ & $13 / 06 / 2014$ \\
\hline & $99902.000258 / 2014-13$ & $20 / 06 / 2014$ \\
\hline & $99902.000180 / 2014-37$ & $24 / 06 / 2014$ \\
\hline & 99902.002140/2013-49 & $14 / 07 / 2014$ \\
\hline & $99902.000725 / 2014-13$ & $14 / 07 / 2014$ \\
\hline & 99902.000579/2014-18 & $05 / 08 / 2014$ \\
\hline & $99902.000497 / 2014-73$ & $09 / 09 / 2014$ \\
\hline & $99902.000684 / 2014-57$ & $10 / 09 / 2014$ \\
\hline & $99902.001202 / 2014-86$ & $26 / 09 / 2014$ \\
\hline & 99902.001015/2014-01 & $26 / 09 / 2014$ \\
\hline & $99902.001070 / 2014-92$ & $02 / 10 / 2014$ \\
\hline & $99902.001005 / 2014-67$ & $08 / 10 / 2014$ \\
\hline & $99902.000431 / 2014-83$ & $30 / 10 / 2014$ \\
\hline & $99902.000720 / 2014-82$ & $08 / 12 / 2014$ \\
\hline & 99902.001279/2014-56 & $08 / 12 / 2014$ \\
\hline & 99902.001290/2014-16 & $15 / 12 / 2014$ \\
\hline & 99902.001745/2014-01 & $16 / 01 / 2015$ \\
\hline & 99902.001978/2014-04 & $24 / 03 / 2015$ \\
\hline & $99902.000300 / 2015-87$ & $06 / 05 / 2015$ \\
\hline & $99902.001719 / 2014-75$ & $18 / 06 / 2015$ \\
\hline & $99902.000836 / 2015-01$ & $29 / 07 / 2015$ \\
\hline & $99902.001747 / 2015-73$ & $31 / 07 / 2015$ \\
\hline
\end{tabular}




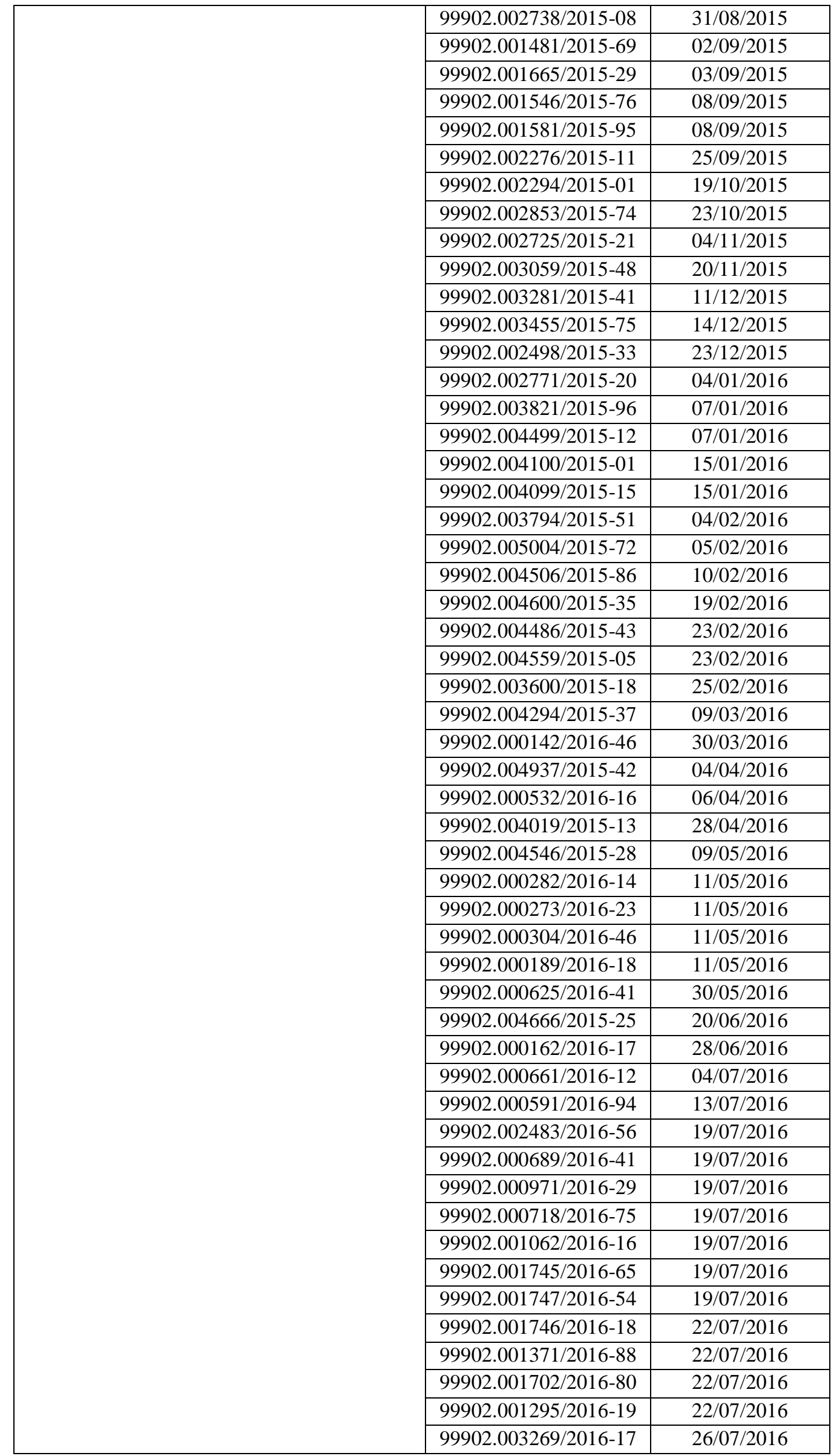




\begin{tabular}{|c|c|c|}
\hline & $99902.001893 / 2016-80$ & $04 / 08 / 2016$ \\
\hline & $99902.003266 / 2016-83$ & $15 / 08 / 2016$ \\
\hline & $99902.003271 / 2016-96$ & $15 / 08 / 2016$ \\
\hline & $99902.003268 / 2016-72$ & $15 / 08 / 2016$ \\
\hline & $99902.003674 / 2016-35$ & $15 / 08 / 2016$ \\
\hline & $99902.002290 / 2016-03$ & $15 / 08 / 2016$ \\
\hline & $99902.001639 / 2016-81$ & $15 / 08 / 2016$ \\
\hline & $99902.003740 / 2016-77$ & $22 / 08 / 2016$ \\
\hline & $99902.003226 / 2016-31$ & $22 / 08 / 2016$ \\
\hline & $99902.002876 / 2016-60$ & $24 / 08 / 2016$ \\
\hline & $99902.002077 / 2016-93$ & $31 / 08 / 2016$ \\
\hline & $99902.002735 / 2016-47$ & $19 / 10 / 2016$ \\
\hline & $99902.004436 / 2016-47$ & $08 / 11 / 2016$ \\
\hline & $99902.003996 / 2016-84$ & $11 / 11 / 2016$ \\
\hline & $99902.003994 / 2016-95$ & $11 / 11 / 2016$ \\
\hline & $99902.004280 / 2016-02$ & $22 / 11 / 2016$ \\
\hline & $99902.004483 / 2016-91$ & $22 / 11 / 2016$ \\
\hline & $99902.005041 / 2016-61$ & $09 / 12 / 2016$ \\
\hline & $99902.004295 / 2016-62$ & $09 / 12 / 2016$ \\
\hline & $99902.004296 / 2016-15$ & $09 / 12 / 2016$ \\
\hline & $99902.004278 / 2016-25$ & $22 / 12 / 2016$ \\
\hline & $99902.003527 / 2016-65$ & $02 / 01 / 2017$ \\
\hline & $99902.005484 / 2016-52$ & $09 / 01 / 2017$ \\
\hline & $99902.005485 / 2016-05$ & $09 / 01 / 2017$ \\
\hline & $99902.005486 / 2016-41$ & $09 / 01 / 2017$ \\
\hline & $99902.005611 / 2016-13$ & $27 / 01 / 2017$ \\
\hline & $99902.004985 / 2016-11$ & $03 / 02 / 2017$ \\
\hline & $99902.004983 / 2016-22$ & $03 / 02 / 2017$ \\
\hline & $99902.004965 / 2016-41$ & $07 / 02 / 2017$ \\
\hline & $99902.004966 / 2016-95$ & $07 / 02 / 2017$ \\
\hline & $99902.004970 / 2016-53$ & $07 / 02 / 2017$ \\
\hline & $99902.005102 / 2016-91$ & $24 / 02 / 2017$ \\
\hline CEITEC/S.A. - Centro Nacional de & $99931.000012 / 2014-02$ & $20 / 06 / 2014$ \\
\hline Tecnologia Eletrônica Avançada S.A. & $99931.000013 / 2014-49$ & $20 / 06 / 2014$ \\
\hline & $99931.000014 / 2014-93$ & $11 / 08 / 2014$ \\
\hline & $99931.000011 / 2015-31$ & $29 / 07 / 2015$ \\
\hline & $99931.000033 / 2016-81$ & $26 / 07 / 2016$ \\
\hline CGTEE - Companhia de Geração Térmica de & $99908.000226 / 2015-49$ & $29 / 07 / 2015$ \\
\hline Energia Elétrica & $99908.000650 / 2015-93$ & $10 / 03 / 2016$ \\
\hline DATAPREV - Empresa de Tecnologia e & $37400.010149 / 2013-27$ & $17 / 12 / 2013$ \\
\hline Informações da Previdência Social & $37400.001930 / 2014-91$ & $16 / 06 / 2014$ \\
\hline & $37400.001932 / 2014-81$ & $16 / 06 / 2014$ \\
\hline EBC - Empresa Brasileira de Comunicação & $99936.000072 / 2014-77$ & $01 / 10 / 2014$ \\
\hline ECT - Empresa Brasileira de Correios e & $99923.000358 / 2013-11$ & $12 / 08 / 2013$ \\
\hline Telégrafos & $99923.001660 / 2013-96$ & $24 / 07 / 2014$ \\
\hline & $99923.001052 / 2014-62$ & $22 / 08 / 2014$ \\
\hline & $99923.001372 / 2014-12$ & $03 / 10 / 2014$ \\
\hline & $99923.001703 / 2014-14$ & $13 / 02 / 2015$ \\
\hline & $99923.000235 / 2015-41$ & $07 / 04 / 2015$ \\
\hline & $99923.000047 / 2015-13$ & $19 / 06 / 2015$ \\
\hline & $99923.000089 / 2015-54$ & $23 / 06 / 2015$ \\
\hline
\end{tabular}




\begin{tabular}{|c|c|c|}
\hline & $99923.000087 / 2015-65$ & $23 / 06 / 2015$ \\
\hline & $99923.000088 / 2015-18$ & $23 / 06 / 2015$ \\
\hline & $99923.000691 / 2015-91$ & $27 / 07 / 2015$ \\
\hline & $99923.000486 / 2015-26$ & $20 / 08 / 2015$ \\
\hline & $99923.001026 / 2015-15$ & $19 / 10 / 2015$ \\
\hline & $99923.001633 / 2015-85$ & $10 / 02 / 2016$ \\
\hline & $99923.001482 / 2015-65$ & $15 / 02 / 2016$ \\
\hline & $99923.001226 / 2015-78$ & $11 / 03 / 2016$ \\
\hline & $99923.001636 / 2015-19$ & $11 / 03 / 2016$ \\
\hline & $99923.000026 / 2016-89$ & $15 / 07 / 2016$ \\
\hline & $99923.000029 / 2016-12$ & $15 / 07 / 2016$ \\
\hline & $99923.000041 / 2016-27$ & $15 / 07 / 2016$ \\
\hline & $99923.000032 / 2016-36$ & $15 / 07 / 2016$ \\
\hline & $99923.000033 / 2016-81$ & $15 / 07 / 2016$ \\
\hline & $99923.000037 / 2016-69$ & $15 / 07 / 2016$ \\
\hline & $99923.000043 / 2016-16$ & $15 / 07 / 2016$ \\
\hline & $99923.000047 / 2016-02$ & $15 / 07 / 2016$ \\
\hline & $99923.000653 / 2016-10$ & $22 / 07 / 2016$ \\
\hline & $99923.000045 / 2016-13$ & $22 / 08 / 2016$ \\
\hline & $99923.000506 / 2016-40$ & $02 / 09 / 2016$ \\
\hline & $99923.001498 / 2016-59$ & $20 / 01 / 2017$ \\
\hline & $99923.001407 / 2016-85$ & $06 / 02 / 2017$ \\
\hline & $99923.001555 / 2016-08$ & $13 / 02 / 2017$ \\
\hline & 99923.001405/2016-96 & $23 / 02 / 2017$ \\
\hline ELETROBRÁS - Centrais Elétricas & $99908.000137 / 2012-50$ & $12 / 12 / 2012$ \\
\hline Brasileiras S.A. & $99908.000019 / 2015-94$ & $05 / 05 / 2015$ \\
\hline & $99908.000604 / 2016-75$ & $28 / 12 / 2016$ \\
\hline ELETROSUL - Eletrosul Centrais Elétricas & $99908.000244 / 2013-69$ & $31 / 10 / 2013$ \\
\hline S.A. & $99908.000257 / 2013-38$ & $05 / 03 / 2014$ \\
\hline & $99908.000256 / 2014-74$ & $22 / 09 / 2014$ \\
\hline & $99908.000255 / 2014-20$ & $22 / 09 / 2014$ \\
\hline & $99908.000163 / 2015-21$ & $29 / 07 / 2015$ \\
\hline & $99908.000727 / 2015-25$ & $01 / 06 / 2016$ \\
\hline EMBRAPA - Empresa Brasileira de Pesquisa & $99937.000055 / 2013-49$ & $12 / 07 / 2013$ \\
\hline Agropecuária & $99937.000247 / 2013-55$ & $09 / 06 / 2014$ \\
\hline EMGEPRON - Empresa Gerencial de & $99925.000008 / 2016-87$ & $01 / 06 / 2016$ \\
\hline Projetos Navais & $99925.000027 / 2015-22$ & $08 / 06 / 2016$ \\
\hline EPE - Empresa de Pesquisa Energética & $99938.000080 / 2014-01$ & $17 / 04 / 2015$ \\
\hline & $99938.000044 / 2016-00$ & $15 / 08 / 2016$ \\
\hline FINEP - Financiadora de Estudos e Projetos & $99906.000148 / 2013-31$ & $06 / 06 / 2014$ \\
\hline FURNAS - Furnas Centrais Elétricas S.A. & $99908.000232 / 2015-04$ & $29 / 07 / 2015$ \\
\hline & $99908.000428 / 2015-91$ & $29 / 10 / 2015$ \\
\hline $\begin{array}{r}\text { HEMOBRÁS - Empresa Brasileira de } \\
\text { Hemoderivados e Biotecnologia }\end{array}$ & $99926.000025 / 2014-42$ & $23 / 02 / 2015$ \\
\hline IMBEL - Indústria de Material Bélico do & $99940.000019 / 2012-45$ & $15 / 03 / 2013$ \\
\hline Brasil & $99940.000007 / 2015-63$ & $31 / 07 / 2015$ \\
\hline & $99940.000039 / 2016-40$ & $19 / 07 / 2016$ \\
\hline INFRAERO - Empresa Brasileira de & $99927.000266 / 2015-62$ & $15 / 02 / 2016$ \\
\hline Infraestrutura Aeroportuária & $99927.000275 / 2015-53$ & $17 / 03 / 2016$ \\
\hline & $99927.000255 / 2015-82$ & $06 / 04 / 2016$ \\
\hline & $99927.000029 / 2016-82$ & $25 / 04 / 2016$ \\
\hline
\end{tabular}




\begin{tabular}{|c|c|c|}
\hline & $99927.000084 / 2016-72$ & $11 / 07 / 2016$ \\
\hline $\begin{array}{r}\text { NUCLEP - Nuclebrás Equipamentos Pesados } \\
\text { S.A. }\end{array}$ & $01390.001248 / 2015-07$ & $30 / 11 / 2015$ \\
\hline \multirow[t]{31}{*}{ PETROBRAS - Petróleo Brasileiro S.A. } & $99909.000070 / 2013-24$ & $10 / 09 / 2013$ \\
\hline & $99909.000115 / 2013-61$ & $23 / 10 / 2013$ \\
\hline & $99909.000184 / 2013-74$ & $25 / 10 / 2013$ \\
\hline & $99909.000123 / 2014-98$ & $26 / 09 / 2014$ \\
\hline & $99909.000125 / 2014-87$ & $16 / 01 / 2015$ \\
\hline & $99909.000109 / 2014-94$ & $16 / 01 / 2015$ \\
\hline & $99909.000117 / 2015-11$ & $09 / 07 / 2015$ \\
\hline & $99909.000025 / 2015-31$ & $21 / 07 / 2015$ \\
\hline & $99909.000026 / 2015-86$ & $21 / 07 / 2015$ \\
\hline & $99909.000027 / 2015-21$ & $21 / 07 / 2015$ \\
\hline & $99909.000028 / 2015-75$ & $21 / 07 / 2015$ \\
\hline & $99909.000029 / 2015-10$ & $21 / 07 / 2015$ \\
\hline & $99909.000030 / 2015-44$ & $21 / 07 / 2015$ \\
\hline & $99909.000031 / 2015-99$ & $21 / 07 / 2015$ \\
\hline & $99909.000032 / 2015-33$ & $21 / 07 / 2015$ \\
\hline & $99909.000033 / 2015-88$ & $21 / 07 / 2015$ \\
\hline & $99909.000034 / 2015-22$ & $21 / 07 / 2015$ \\
\hline & $99909.000035 / 2015-77$ & $21 / 07 / 2015$ \\
\hline & $99909.000036 / 2015-11$ & $21 / 07 / 2015$ \\
\hline & $99909.000251 / 2015-12$ & $27 / 07 / 2015$ \\
\hline & $99909.000344 / 2016-28$ & $25 / 05 / 2016$ \\
\hline & $99909.000345 / 2016-72$ & $25 / 05 / 2016$ \\
\hline & $99909.000346 / 2016-17$ & $25 / 05 / 2016$ \\
\hline & $99909.000347 / 2016-61$ & $25 / 05 / 2016$ \\
\hline & 99909.000348/2016-14 & $25 / 05 / 2016$ \\
\hline & $99909.000461 / 2016-91$ & $25 / 08 / 2016$ \\
\hline & $99909.000462 / 2016-36$ & $25 / 08 / 2016$ \\
\hline & 99909.000931/2016-17 & $12 / 12 / 2016$ \\
\hline & $99909.000930 / 2016-72$ & $04 / 01 / 2017$ \\
\hline & 99909.000932/2016-61 & $04 / 01 / 2017$ \\
\hline & $99909.001036 / 2016-10$ & $06 / 02 / 2017$ \\
\hline \multirow{5}{*}{$\begin{array}{r}\text { SERPRO - Serviço Federal de } \\
\text { Processamento de Dados }\end{array}$} & $99928.000115 / 2012-51$ & $08 / 04 / 2013$ \\
\hline & $99928.000116 / 2012-04$ & $08 / 04 / 2013$ \\
\hline & $99928.000141 / 2015-22$ & $26 / 05 / 2015$ \\
\hline & $99928.000499 / 2015-55$ & $10 / 07 / 2015$ \\
\hline & $99928.000496 / 2015-11$ & $21 / 07 / 2015$ \\
\hline \multirow{2}{*}{$\begin{array}{r}\text { TELEBRÁS - Telecomunicações Brasileiras } \\
\text { S.A. }\end{array}$} & 99929.000035/2013-77 & $25 / 02 / 2014$ \\
\hline & $99929.000026 / 2015-48$ & $29 / 07 / 2015$ \\
\hline
\end{tabular}


